列

\title{
Lanthana-Doped Ceria as Active Support for Oxygen Carriers in Chemical
}

\section{Looping Combustion}

\author{
Saurabh Bhavsar ${ }^{1,2}$, Natalie Isenberg ${ }^{1}$, Amey More ${ }^{1}$ and Götz Veser ${ }^{1,2, *}$ \\ ${ }^{1}$ Chemical Engineering Department, Swanson School of Engineering, University of Pittsburgh, \\ Pittsburgh, PA 15261 \\ ${ }^{2}$ U.S. Department of Energy - National Energy Technology Laboratory, Pittsburgh, PA
}

Abstract:

The redox properties and oxygen buffering capacity of reducible oxides, such as ceria, make them interesting support materials for oxygen carriers in chemical looping combustion (CLC), an emerging clean combustion technology. However, the effectiveness of reducible oxides for redox applications depends crucially on oxygen mobility in the oxide lattice. In the present work, we demonstrate that addition of an aliovalent dopant (La) strongly enhances oxygen mobility in ceria, resulting in multiple performance benefits. A series of La-doped ceria $\left(\mathrm{La}_{\mathrm{x}} \mathrm{Ce}_{1-\mathrm{x}} \mathrm{O}_{2-\mathrm{x} / 2}, 0<\right.$ $\mathrm{x}<0.3)$ were investigated as supports for low-cost Fe-based oxygen carrier materials. Combining carrier synthesis and characterization with reactive tests, we demonstrate that La doping of ceria not only results in a drastic improvements in carrier reactivity and oxygen carrying capacity, but also strongly improved carrier stability during redox cycling. This is consistent with the creation of oxygen defects, which stabilize the supported Fe particles and facilitate oxygen transport in the ceria lattice. A balance between enhancement of oxygen 1 mobility and lowered reducibility upon formation of a lanthana phase results in a strongly nonlinear dependence of carrier reactivity on the dopant concentration and gives rise to an

\footnotetext{
* Corresponding Author: Götz Veser (gveser@pitt.edu)
} 
23 optimum at low dopant concentrations. Overall, the results suggest that doping of reducible

24 supports constitutes a highly attractive, effective, and low-cost way to strongly enhance the 25 performance of oxygen carriers in chemical looping applications.

26

27 Keywords: Chemical looping combustion, $\mathrm{CO}_{2}$ capture, iron, ceria, lanthana, doping. 


\section{Introduction:}

29 Increasing supply of energy is imperative for continued growth of modern society, particularly in the so-called developing world. The International Energy Agency (IEA) predicts that global

31 primary energy demand will increase by almost $20 \%$ over the next 15 years alone. Although the

32 share of fossil fuels is predicted to decrease slightly from $82 \%$ now to $76 \%$ by 2035 , energy-

33 related $\mathrm{CO}_{2}$ emissions are expected to rise by $20 \%$ over the same time-frame ${ }^{1,2}$. As the source of

34 two-thirds of the global greenhouse-gas emissions, technological advances in the energy sector

35 will be pivotal in abating $\mathrm{CO}_{2}$ emissions. Given our dependence on fossil fuels, alternative technology solutions for clean combustion of fossil fuels with simultaneous $\mathrm{CO}_{2}$ capture should

37 hence have high priority in our energy R\&D landscape.

38 Chemical Looping Combustion (CLC) has emerged over the past decade as a particularly 39 promising technology in this context, offering a highly efficient route for clean combustion of 40 fossil fuels with inherent $\mathrm{CO}_{2}$ capture ${ }^{3-5}$. In CLC, an oxygen carrier (typically a metal oxide) is 41 contacted with fuel in a first reactor (fuel reactor), undergoing reduction while providing the 42 necessary oxygen for combustion of fuel (Figure 1). After combustion, the reduced metal is 43 transferred to the second reactor (air reactor) where it is re-oxidized in contact with air. The 44 oxidized metal is then circulated back to the fuel reactor, closing the material 'loop'. In the fuel 45 reactor, ideally, a pure mixture of $\mathrm{CO}_{2}$ and $\mathrm{H}_{2} \mathrm{O}$ is formed as combustion gases, from which 46 high-concentration, sequestration ready $\mathrm{CO}_{2}$ streams can be readily obtained via condensation of 47 steam. Thus, CLC offers a unique and efficient route for $\mathrm{NO}_{x}$-lean, flameless combustion of 48 fossil fuels with inherent $\mathrm{CO}_{2}$ capture at minimal efficiency penalty for $\mathrm{CO}_{2}$ capture, making it 49 rather unique among current and emerging $\mathrm{CO}_{2}$ capture technologies ${ }^{6-9}$. 


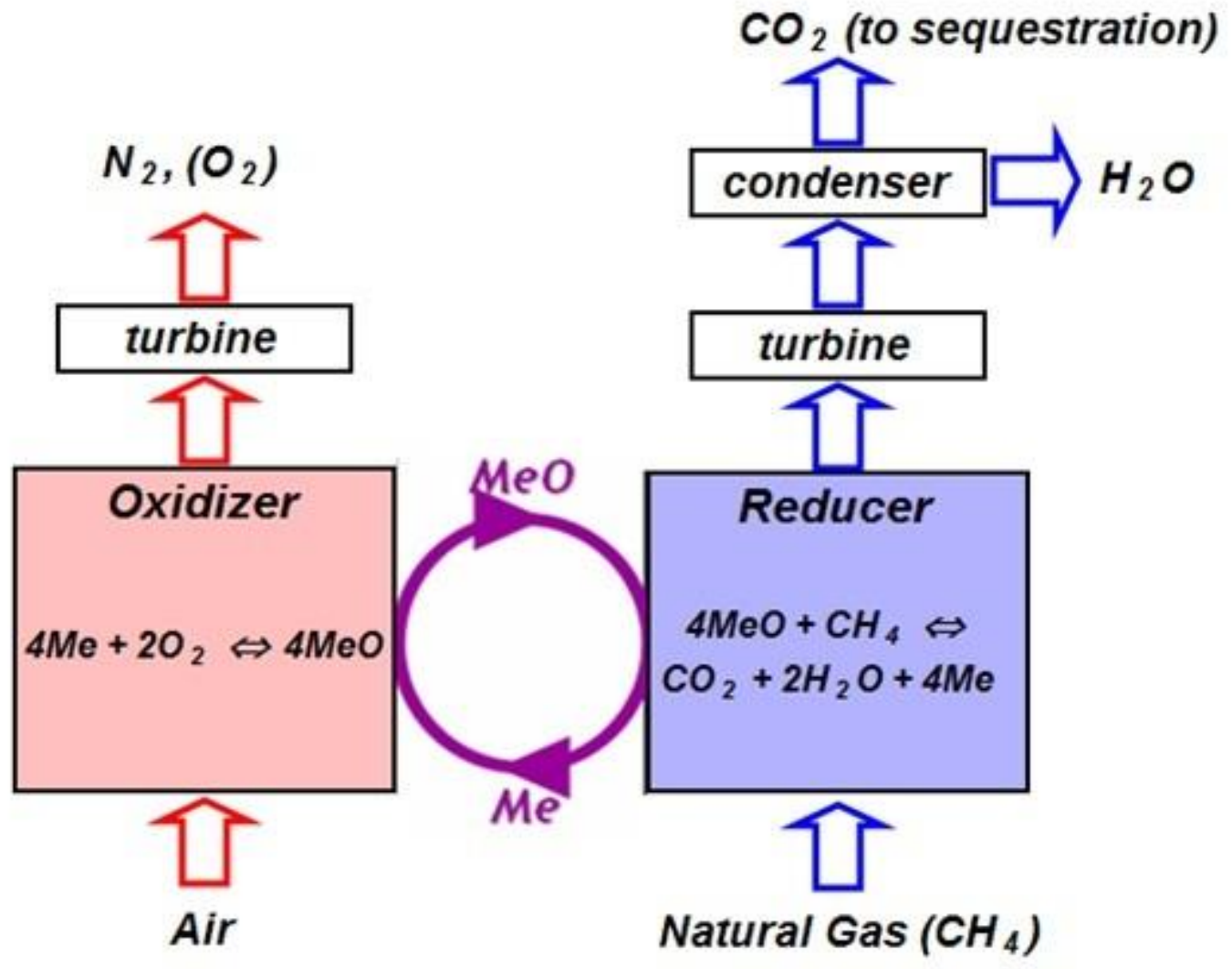

Figure 1: Schematic for CLC using $\mathrm{CH}_{4}$ as fuel 
52 Although the concept of CLC has been demonstrated widely ${ }^{10-17}$, there is still need for

53 improvement in the design of efficient oxygen carriers, with sufficient carrier stability and fast

54 redox kinetics as key issues. Depending on the reactor configuration used for CLC, continuous

55 cycling of particles between reduced and oxidized states subjects the oxygen carriers to

56 chemical, thermal and mechanical stress in transport reactor configurations. Consequently, vast

57 efforts have been dedicated to developing efficient oxygen carriers that can cope with the harsh

58 environment of CLC. Most of the oxygen carriers reported in the literature are synthetic carrier

59 materials. $\mathrm{Cu}-, \mathrm{Ni}-, \mathrm{Fe}-, \mathrm{Mn}-$, and $\mathrm{Co}-$ based oxygen carriers have been investigated for their

60 thermal stability and reactivity ${ }^{18-22}$, with their thermal stability typically improved by supporting

61 the active metal on inert oxide supports such as $\mathrm{Al}_{2} \mathrm{O}_{3}, \mathrm{SiO}_{2}, \mathrm{ZrO}_{2}$, and $\mathrm{MgAl}_{2} \mathrm{O}_{4}{ }^{10},{ }^{23-27}$.

62 Although these inert oxides can be quite effective in rendering the supported metal thermally

63 stable, they contribute neither to the oxygen carrying capacity nor the redox kinetics for the

64 composite carrier. Instead, the significant mass fraction of an oxygen carrier represented by a

65 non-reducible support results in additional energy demand required in handling such carrier

66 materials during looping operations. Recent work by our own group ${ }^{28-30}$ and others ${ }^{31-33}$ has

67 shown that such inert support materials can be replaced by "active" reducible support materials,

68 such as ceria or perovskites ${ }^{60-62}$. In our previous work, we observed that use of reducible oxides

69 as supports is highly advantageous since it i) facilitates complete utilization of the supported

70 metal, ii) results in faster redox kinetics, and iii) stabilizes the metal phase in bimetallic carriers

71 without resulting in the formation of undesired spinel structures (which are typically inactive in

72 redox processes) ${ }^{29,30}$.

73 Although the use of reducible oxides as supports is a recent concept in CLC, use of "active"

74 supports is well established in the field of heterogeneous catalysis where reducible oxides, in 
75 particular ceria, are widely used as support for metal nanoparticles in various catalytic redox 76 reactions $^{34}$, including automotive exhaust clean-up (catalytic convertor) ${ }^{35}$, water gas shift 77 reaction $^{36,37}$ and catalytic methane oxidation ${ }^{38-40}$. In those applications, the promotional effects 78 of ceria as support can be traced back to strong metal-support interactions ${ }^{41}$ and oxygen 79 buffering, i.e, the facile and reversible release of lattice oxygen via the $\mathrm{Ce}^{4+} \Leftrightarrow \mathrm{Ce}^{3+}$ 80 transformation $^{42}$. Ceria also finds applications as a solid electrolyte in high temperature 81 electrochemical devices such as solid oxide fuel cells (SOFCs), due to its excellent electronic 82 conductivity ${ }^{43,44}$. The overall performance of ceria in these applications is further improved by 83 creation of oxygen vacancies or defects, typically achieved via doping, which influences both 84 oxygen as well as electron transport in the ceria lattice. In particular, doping ceria with cations 85 with significantly different cationic radii than $\mathrm{Ce}$ (such as zirconia, $\mathrm{Zr}^{4+}, 38,45$ ) or with aliovalent 86 dopants such as $\mathrm{La}^{3+39,46}$ has been shown to promote redox properties by facilitating oxygen 87 transport in the ceria lattice, where a strong relation between concentration of oxygen defects and 88 oxygen carrying capacity exists ${ }^{36,47}$. Such doping is also known to improve the thermal 89 stability/textural properties of the support oxides $38,39,45,46,48$. Finally, addition of rare earth 90 dopants $\left(\mathrm{Sm}^{3+}, \mathrm{Gd}^{3+}, \mathrm{Y}^{3+}\right)$ to $\mathrm{CeO}_{2}$ has been reported to result in improved overall ionic 91 conductivity and reducibility ${ }^{49,50}$, with optimal concentrations depending on the kind of dopant ${ }^{51-}$ $92 \quad 53$.

93 However, the effect of ceria doping on redox kinetics and/or carrier stability has not found much 94 attention to-date in the chemical looping community. A sole study from the Chalmer's group ${ }^{31}$ 95 investigated the effect of using ceria and 10\% Gd-doped ceria (in comparison to conventional 96 non-reducible alumina support) for iron-, copper-, and manganese-based carriers. The authors 97 report that doped ceria particles were more reactive than pure ceria. However, the effect of 
98 dopant concentration on redox behavior, carrier stability, and oxygen carrying capacity of 99 oxygen carriers in CLC was not investigated - and the role of such dopants in the redox 100 mechanism at CLC conditions as well as the optimal concentration of (typically more expensive) 101 dopants required to observe the enhancement effects remained hence unexplored.

102 Doped ceria has recently also found some application in concentrated solar power (CSP), a 103 closely related technology in which thermal decomposition of the oxide replaces the chemical 104 reduction step. For example, Haile and coworkers tested 15\% samarium-doped ceria for solar105 thermal $\mathrm{H}_{2} \mathrm{O}$ and $\mathrm{CO}_{2}$ splitting chemistry without, however, further investigating mechanisms 106 and optimal dopant levels ${ }^{33}$. Other CSP studies investigated the impact of dopant concentrations 107 on overall support reducibility, but did not report their effect on redox kinetics ${ }^{54-56}$. However, the 108 operating temperatures $\left(1,000-1,500^{\circ} \mathrm{C}\right)$ are significantly higher than those in typical chemical 109 looping processes $\left(\sim 800-1,000^{\circ} \mathrm{C}\right)$, limiting the transferability of the reported results. Several 110 related studies emphasize phase stability of doped ceria as a limiting factor for the application of 111 these materials, in particular for transition metal dopants ( $\mathrm{Fe}, \mathrm{Cu}, \mathrm{Ni}, \mathrm{Mn})$, due to phase 112 separation via bleed-out of the dopant ${ }^{57,58}$, , reaffirming the need for careful dopant selection 113 and thorough investigation of carrier stability. However, in all these applications, ceria or doped 114 ceria serves as the sole oxygen carrier material, i.e. the redox chemistry is conducted in the 115 absence of (supported) metals. Overall, while the existing work hence suggests that addition of 116 dopants can improve the redox performance of ceria, it points towards a need for a systematic 117 evaluation of the effect of dopant concentration on carrier stability, oxygen carrying capacity, 118 and redox kinetics, in order to enable rational design of optimal oxygen carrier for large-scale 119 CLC applications. 
120 In the present work, we focus on tailoring the reducibility of ceria supports via La doping. La 121 was chosen as a dopant due to the fact that ceria and lanthana have different valances, resulting 122 in the formation of oxygen defect sites in Ce-La solid solutions, as well as due to the fact that we

123 had previously shown that ceria-lanthana solid solutions can be synthesized in a straightforward 124 way over the entire range of Ce:La ratios and show the expected synergistic effects on the oxide 125 reducibility ${ }^{36}$. Iron was chosen as the active (i.e. "oxygen carrying") metal component due to its 126 low toxicity, low cost, and earth abundance, as well as its low intrinsic reactivity which benefits 127 greatly from the use of active support materials. $\mathrm{Fe}-\mathrm{La}_{\mathrm{x}} \mathrm{Ce}_{1-\mathrm{x}} \mathrm{O}_{2-\mathrm{x} / 2}$ carriers were synthesized, 128 characterized, and subjected to redox cycles in a thermogravimetric analyzer and a fixed-bed 129 reactor to establish the effect of doping on the stability, redox kinetics, and oxygen carrying 130 capacity of the carrier.

\section{2. Experimental Section:}

\section{$133 \quad 2.1$ Oxygen Carrier Synthesis:}

134 The main focus in the synthesis of La-doped ceria was not only to attain solid solution of La-Ce

135 but also on simplicity of the synthesis procedure to keep the cost of the resulting material low 136 and hence realistic for industrial application. Oxygen carriers were synthesized using a simple 137 and scalable two-step approach. First, La-doped ceria is synthesized, and then iron is 138 subsequently deposited on the $\mathrm{La}_{\mathrm{x}} \mathrm{Ce}_{1-\mathrm{x}} \mathrm{O}_{2-\mathrm{x} / 2}$ support by deposition-precipitation.

$139 \mathrm{La}_{\mathrm{x}} \mathrm{Ce}_{1-\mathrm{x}} \mathrm{O}_{2-\mathrm{x} / 2}$ supports with varying $\mathrm{La}$ concentration $(0<\mathrm{x}<0.3)$ were prepared via a facile 140 hydrothermal synthesis procedure previously adapted in our research group ${ }^{36}$. For example, $141 \mathrm{La}_{0.1} \mathrm{Ce}_{0.9} \mathrm{O}_{1.95}$ was synthesized by dissolving $0.675 \mathrm{~g}$ of $\mathrm{Ce}\left(\mathrm{NO}_{3}\right)_{3} \cdot 6 \mathrm{H}_{2} \mathrm{O}(99+\%$, Sigma-Aldrich $)$ 142 and $0.075 \mathrm{~g}$ of $\mathrm{La}\left(\mathrm{NO}_{3}\right)_{3} \cdot 6 \mathrm{H}_{2} \mathrm{O}(99+\%$, Sigma-Aldrich) in $8 \mathrm{ml} \mathrm{DI}$ water. $30 \mathrm{ml}$ of $\mathrm{NaOH}(98+\%$, 
143 Sigma-Aldrich) solution (7 M) was rapidly added under vigorous stirring. After 30 min of 144 stirring, the slurry was transferred into a $50 \mathrm{ml}$ autoclave, heated to $100^{\circ} \mathrm{C}$ under autogenous 145 pressure for $72 \mathrm{~h}$, and then allowed to cool to room temperature. The product was washed with 146 DI water and collected via centrifugation to remove any ionic remnants until the $\mathrm{pH}$ of the 147 solution was 7. Finally, the resulting powder was dried at $100^{\circ} \mathrm{C}$ overnight and calcined at $450^{\circ} \mathrm{C}$ 148 for $2 \mathrm{~h}$.

149 Next, Fe-based carriers were synthesized by deposition-precipitation. Briefly, $\mathrm{Fe}\left(\mathrm{NO}_{3}\right)_{3} \cdot 9 \mathrm{H}_{2} \mathrm{O}$ 150 (99+\%, Sigma-Aldrich) was dissolved in DI water, and $40 \mathrm{~mL}$ of the $0.06 \mathrm{M}$ precursor solution 151 was precipitated by $0.5 \mathrm{M} \mathrm{NaOH}$ at $\mathrm{pH}$ of $9-9.5$ on $200 \mathrm{mg}$ of the desired support powder 152 suspended in $100 \mathrm{~mL}$ DI water. After aging for $2 \mathrm{~h}$, the resulting precipitate was centrifuged, 153 vacuum dried at $100^{\circ} \mathrm{C}$, crushed and finally calcined in air at $900^{\circ} \mathrm{C}$ for $2 \mathrm{~h}$ in air.

\subsection{Oxygen Carrier Characterization:}

156 To understand the effect of redox cycling, the carriers were carefully characterized after 157 synthesis, reactive tests in TGA, and after fixed-bed reactor tests. The specific surface area of the 158 oxygen carriers was obtained via nitrogen sorption in a Micromeritics ASAP 2020 gas 159 adsorption analyzer using the BET method. Prior to the measurement, the samples were degassed 160 for $2 \mathrm{~h}$ at $200^{\circ} \mathrm{C}$ under high vacuum. After calcination at $450^{\circ} \mathrm{C}$ for $2 \mathrm{~h}$, all the support oxide 161 materials were found to have total surface area between $70-90 \mathrm{~m}^{2} / \mathrm{g}$. Further calcination of the

162 final $\mathrm{Fe}-\mathrm{La}_{\mathrm{x}} \mathrm{Ce}_{1-\mathrm{x}} \mathrm{O}_{2-\mathrm{x} / 2}$ carriers calcined at $900^{\circ} \mathrm{C}$ reduced the surface area to $<7 \mathrm{~m}^{2} / \mathrm{g}$. The drop 163 in surface area upon calcination is due to the well-known limitations in high-temperature 164 stability of ceria supports ${ }^{38,39,45,46}$. X-ray diffraction (XRD) measurements were performed with 
165 a powder X-ray diffractometer (Phillips PW1830) in line focus mode employing $\mathrm{Cu} \mathrm{K} \alpha$ radiation

$166(\lambda=1.5418 \AA)$ with typical $2 \theta$ scans between $15^{\circ}$ and $90^{\circ}$. Crystal phases were identified based

167 on JCPDS cards. Average crystal lattice spacings were determined using Bragg's law.

168

169

170

171

172

173

174

175

176

177

178

179

180

181

182

183

184

185

186

187

\subsection{CLC Reactive Tests:}

\subsubsection{Thermogravimetric Analyzer (TGA) Tests:}

In first tests, pure $\mathrm{H}_{2}$ was used as a model fuel to characterize carrier performance during redox cycles without the added complexity of carbon formation that often accompanies the use of methane as fuel. Kinetics and thermal stability of the carriers with $\mathrm{H}_{2}$ as fuel were evaluated in thermogravimetric analyzer tests (TA instruments, SDTQ600). Subsequently, thermal stability and kinetic tests were conducted with $\mathrm{CH}_{4}$ as fuel. Reduction half cycles were carefully timed to avoid carbon formation on the carrier material and possible undesired carbon carry-over from the reducer to the oxidizer.

In a typical run, up to $20 \mathrm{mg}$ of oxygen carriers were heated inside the TGA cradle in an inert gas stream (Ar, Grade 5.0) to the desired reaction temperature $\left(900^{\circ} \mathrm{C}\right)$. Then, $\mathrm{H}_{2}(\mathrm{Grade} 5.0)$ and air (Grade 0.1 ) were fed alternatingly at a flowrate of $20 \mathrm{sccm}$ to simulate the periodic reductionoxidation cycles of CLC. Between reduction and oxidation phases, the TGA was purged with Ar (20 sccm, Grade 5.0) to avoid formation of potentially flammable gas mixtures inside the instrument. In $\mathrm{CLC}$ with $\mathrm{CH}_{4}$ as fuel (Grade 2.0, $5 \mathrm{sccm}$ ), suitable reduction times were determined by varying the duration of the reduction half cycle and the $\mathrm{CH}_{4}$ flowrate while monitoring the occurrence of carbon burn-off in the oxidation half cycle. All other experimental conditions were identical as explained above for $\mathrm{H}_{2}$. Up to 50 redox cycles were conducted in the 
188 TGA experiments in order to identify trends in the stable operation or reveal any deactivation in 189 the oxygen carrier performance and carrier conversion. All experiments were conducted at 190 ambient pressure conditions.

\subsubsection{Fixed-bed Reactor tests:}

194 Oxygen carriers were evaluated in a fixed-bed reactor to investigate the effect of La-doping on 195 carrier activity and selectivity in converting methane to steam and carbon dioxide. $100 \mathrm{mg}$ of Fe$196 \mathrm{La}_{\mathrm{x}} \mathrm{Ce}_{1-\mathrm{x}} \mathrm{O}_{2-\mathrm{x} / 2}$ powder was placed inside a quartz-glass tubular reactor (1/4” ID), which was 197 inserted into an electric oven (Thermo Electron Corporation - Lindberg/Blue M). The bed was 198 equipped with a coke-resistant high temperature stable thermocouple to measure the actual bed 199 temperature. The oven was heated to $900^{\circ} \mathrm{C}$ and $\mathrm{CH}_{4}\left(1 \mathrm{sccm}\right.$, Grade $2.0, \mathrm{y}_{\mathrm{CH} 4}=16.7 \%$ in $\left.\mathrm{Ar}\right)$ 200 and $20 \% \mathrm{O}_{2}$ in balance $\mathrm{He}(20 \mathrm{sccm})$ were flown alternatingly to simulate the periodic reduction 201 and oxidation in CLC. In between reduction and oxidation of the carrier, the reactor was purged 202 with argon (Grade 5.0) to avoid formation of explosive mixtures of air and $\mathrm{CH}_{4}$ inside the reactor 203 and facilitate evaluation of distinct oxidation and reduction phases. After condensation of 204 moisture, the effluent gases were recorded using a mass spectrometer (Pfeiffer Omnistar QMS 205 200) and the data was converted to molar flowrates $\left(\mathrm{n}_{\mathrm{i}}\right)$ for all species observed during the 206 reaction. A carbon balance was performed to assure the accuracy of the analysis and closed 207 within 5-10\% error for all reported experiments.

208 Carbon Balance:

209

$$
n_{C_{4, \text { in }}}=n_{C_{4, \text { out }}}+n_{C_{2, \text { out }}}+n_{C_{\text {out }}}+0.5 \times\left(n_{H_{2, \text { out }}}-2 n_{C_{\text {out }}}\right)
$$


210 On-stream methane conversion $\left(\mathrm{X}_{\mathrm{CH} 4}\right)$ and cumulative carrier $\left(\mathrm{X}_{\text {carrier }}\right)$ conversion were evaluated

211 using:

212

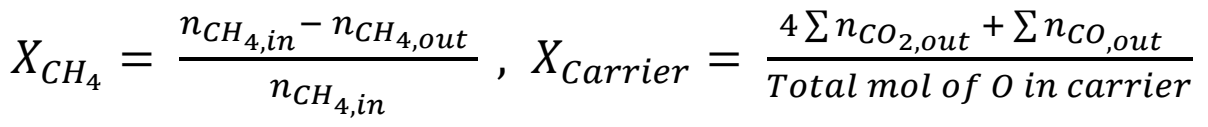

213 Selectivity of various species $\left(\mathrm{S}_{\mathrm{i}}\right)$ viz. $\mathrm{CO}_{2}, \mathrm{H}_{2}, \mathrm{CO}$ and carbon (C) formation by methane

214 pyrolysis were calculated by the following equations.

$215 S_{\mathrm{CO}_{2}}=\frac{n_{\mathrm{CO}_{2, \text { out }}}}{\left(n_{\mathrm{CH}_{4, \text { in }}}-n_{\mathrm{CH}_{4, \text { out }}}\right)}, S_{\mathrm{CO}}=\frac{n_{\mathrm{CO}_{\text {out }}}}{\left(n_{\mathrm{CH}_{4, \text { in }}}-n_{\mathrm{CH}_{4, \mathrm{out}}}\right)}$

$216 S_{H_{2}}=\frac{0.5 n_{H_{2, \text { out }}}}{\left(n_{\mathrm{CH}_{4, \text { in }}}-n_{\mathrm{CH}_{4, \text { out }}}\right)}, S_{\text {Carbon }}=\frac{0.5\left(n_{H_{2, \text { out }}}-2 n_{C O_{\text {out }}}\right)}{\left(n_{\mathrm{CH}_{4, \text { in }}}-n_{\mathrm{CH}_{4, \mathrm{out}}}\right)}$

217 As expected, total oxidation, partial oxidation and catalytic pyrolysis of methane were found to

218 be the dominant reactions occurring in the system, illustrated schematically in the following

219 reactions where "MeO" is a metal oxide and "Me" the corresponding reduced metal:

220 Total Oxidation: $\quad \mathrm{CH}_{4}+4 \mathrm{MeO} \Leftrightarrow 4 \mathrm{Me}+\mathrm{CO}_{2}+2 \mathrm{H}_{2} \mathrm{O}$

221 Partial Oxidation: $\quad \mathrm{CH}_{4}+\mathrm{MeO} \Leftrightarrow \mathrm{Me}+\mathrm{CO}+2 \mathrm{H}_{2}$

222 Methane Pyrolysis: $\mathrm{CH}_{4}(+\mathrm{Me}) \Leftrightarrow 2 \mathrm{H}_{2}+\mathrm{C}(+\mathrm{Me})$

3. Results and Discussion:

\subsection{Stability of lanthana-ceria solid solutions}


226 Since understanding the effect of lanthana doping on carrier reactivity is the primary aim of the

227 present study, it is quite essential to first confirm the successful formation and stability of the 228 desired mixed oxides of $\mathrm{La}_{\mathrm{x}} \mathrm{Ce}_{1-\mathrm{x}} \mathrm{O}_{2-\mathrm{x} / 2}$ upon heat treatment and deposition of iron. Therefore, $229 \mathrm{Ce} / \mathrm{La}$ oxides calcined at $450^{\circ} \mathrm{C}$ were first subjected to X-ray diffraction to test for possible co230 existence of separate ceria and lanthana phases which would indicate incomplete incorporation 231 of La into the ceria lattice. Figure 2 shows the diffractograms of various $\mathrm{La}_{\mathrm{x}} \mathrm{Ce}_{1-\mathrm{x}} \mathrm{O}_{2-\mathrm{x} / 2}$ oxides 232 with the dotted vertical lines representing the standard X-ray diffraction angles for pure $\mathrm{CeO}_{2}$ (as 233 obtained from JCPDS PDF \#: 04-0593). One can observe good agreement between reference 234 pattern and $\mathrm{XRD}$ of pure $\mathrm{CeO}_{2}$. Upon doping ceria with lanthana, no separate peaks 235 corresponding to lanthana oxide (or La carbonates, which are known to form rapidly at ambient 236 conditions $^{63}$ ) are observed. Close observation of the diffraction pattern reveals that the 237 diffraction peaks shift to lower angles of reflection with increasing La concentration. 


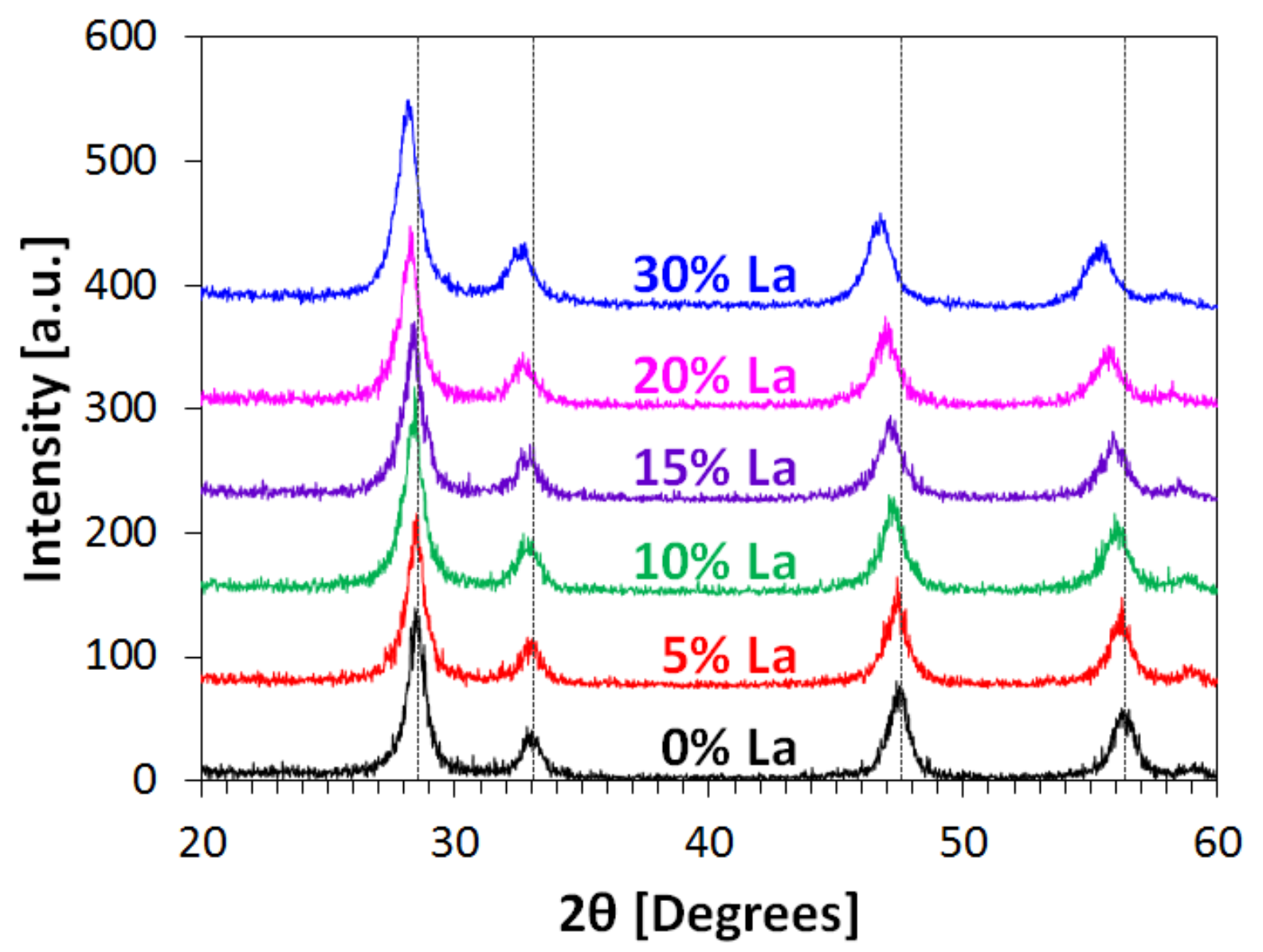

Figure 2: Typical X-ray diffraction pattern of $\mathrm{La}_{\mathrm{x}} \mathrm{Ce}_{1-\mathrm{x}} \mathrm{O}_{2-\mathrm{x} / 2}$ carriers calcined at $450^{\circ} \mathrm{C}$ in air for $2 \mathrm{~h}$. X-ray diffraction confirm peaks corresponding to $\mathrm{CeO}_{2}$ with fluorite structure shifted to higher angle with increasing lanthana concentration, while no lanthanum containing secondary phase are detected. 
239 The peak position for each $\mathrm{La} / \mathrm{Ce}$ oxide allows calculation of the lattice parameters of these 240 support oxides. Figure 3a shows the average lattice parameters for $\mathrm{La}_{\mathrm{x}} \mathrm{Ce}_{1-\mathrm{x}} \mathrm{O}_{2-\mathrm{x} / 2}$ as a function of 241 La-doping $(x=\operatorname{mol~La} /(\mathrm{mol} \mathrm{La}+$ mol Ce $))$. The calculated lattice parameter for pure $\mathrm{CeO}_{2}$ 242 synthesized via the hydrothermal technique $(0.5415 \mathrm{~nm})$ is in close agreement with that of bulk 243 ceria (0.5411 nm, JCPDS PDF \#: 04-0593). Overall, the lattice parameter of the mixed oxides 244 increases with increasing lanthana content due to the larger ionic radius of ${ }^{\mathrm{VIII}} \mathrm{La}^{3+}(1.16 \AA)$ 245 compared to ${ }^{\mathrm{VIII}} \mathrm{Ce}^{4+}(0.97 \AA)^{64}$. (Note that due to the relatively large standard deviation of the 246 lattice parameter for pure $\mathrm{CeO}_{2}$, the value for the $2 \%$ La-doped carrier is statistically unchanged, 247 i.e. the apparent dip is within the error margin of the measurement). Overall, the absence of a 248 separate La-containing phase and the shift of X-ray reflections to a lower angle, i.e. the 249 expansion of ceria lattice upon increasing lanthana concentration, thus confirm successful 250 incorporation of lanthana into the ceria crystal structure. 


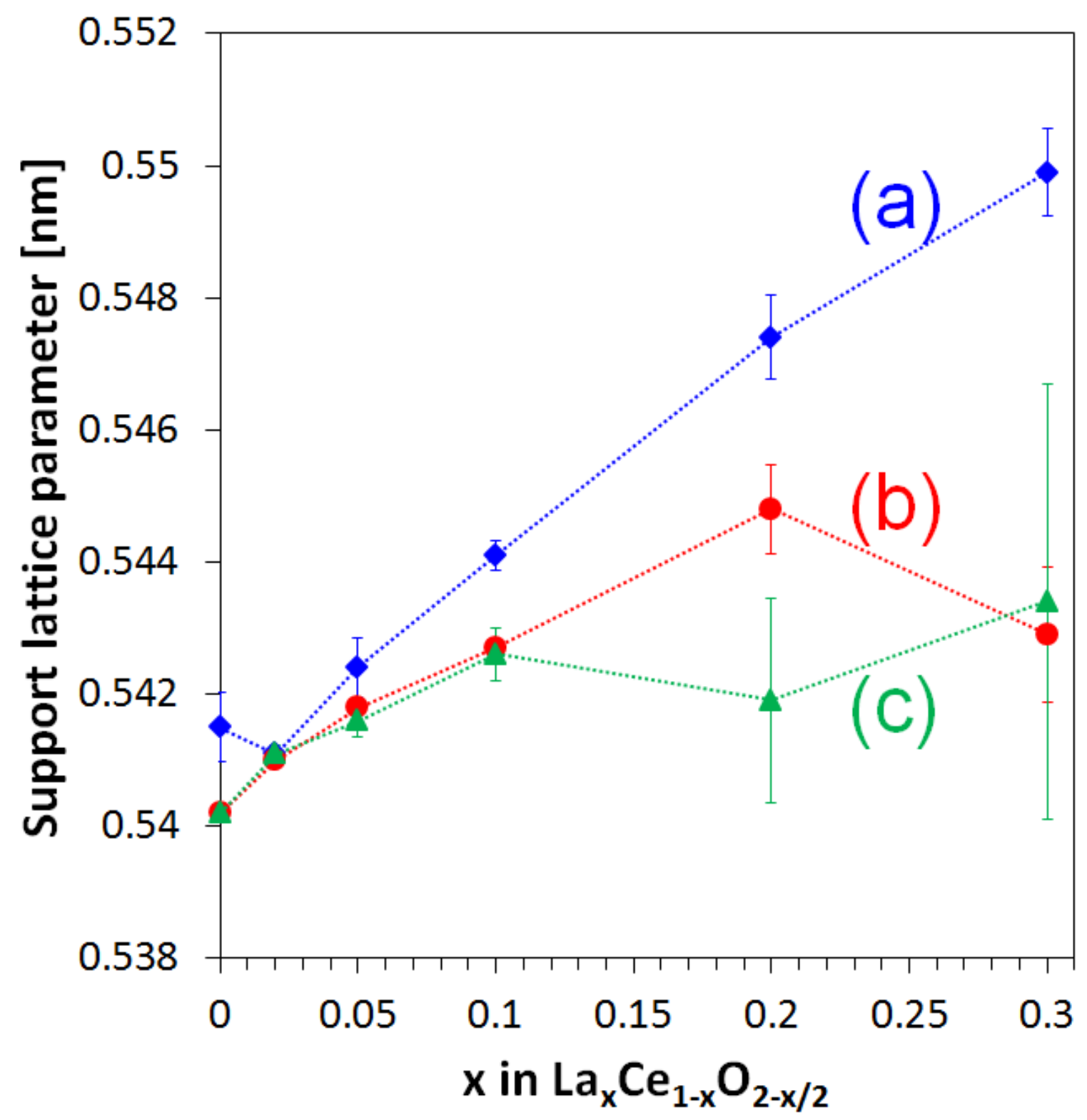

Figure 3: Lattice parameter of $\mathrm{La}_{\mathrm{x}} \mathrm{Ce}_{1-\mathrm{x}} \mathrm{O}_{2-\mathrm{x} / 2}$ oxides after subjecting it to a) air calcination at $450^{\circ} \mathrm{C}, \mathrm{b}$ ) deposition of iron and subsequent calcination in air at $\left.900^{\circ} \mathrm{C}, \mathrm{c}\right)$ TGA redox stability tests of $\mathrm{Fe}-\mathrm{La}_{\mathrm{x}} \mathrm{Ce}_{1-\mathrm{x}} \mathrm{O}_{2-\mathrm{x} / 2}$ at $900^{\circ} \mathrm{C}$ using $\mathrm{H}_{2}$ as fuel. 
253 Upon confirmation of the formation of homogeneous solid solutions of ceria and lanthana for all 254 samples, iron was deposited onto the support powders via deposition-precipitation, and the 255 obtained materials were calcined at $900^{\circ} \mathrm{C}$. Figure 4 shows typical X-ray diffraction patterns for 256 all $\mathrm{Fe}-\mathrm{La}_{\mathrm{x}} \mathrm{Ce}_{1-\mathrm{x}} \mathrm{O}_{2-\mathrm{x} / 2}$ carriers after calcination at $900^{\circ} \mathrm{C}$. Up to $10 \% \mathrm{La}$, only $\mathrm{Fe}_{2} \mathrm{O}_{3}$ and $\mathrm{CeO}_{2}$ are 257 detected (figure 4a-d). Again, no signs for the presence of a separate La-containing phase are 258 apparent and the shift of all the support oxide peaks towards a lower diffraction angle remains 259 unchanged from the Fe-free doped ceria samples, indicating the stability of La in the ceria 260 structure in presence of iron oxide. However, starting at 10\% La doping (figure 4d), XRD shows 261 the appearance of low intensity peaks which indicate formation of $\mathrm{LaFeO}_{3}$. Hence, at higher 262 doping, signatures of lanthana bleed-out from the support structure are observed, although 263 detection of only a few low-intensity X-ray reflections in the XRD pattern of $\mathrm{LaFeO}_{3}$ suggests 264 that the lanthana iron oxide is only a minor phase in the $\mathrm{Fe}-\mathrm{La}_{0.1} \mathrm{Ce}_{0.9} \mathrm{O}_{1.95}$ materials. Further 265 increase in the lanthana concentration gives rise to distinct peaks for $\mathrm{LaFeO}_{3}$ as well as some 266 unassigned peaks in the vicinity of the ceria diffractions at lower diffraction angle (marked by 267 downward arrows in figure 4f). Apparently, once lanthana starts bleeding out of the support 268 structure, the samples contain two ceria phases: ceria that has lost most of the La dopant (which 269 hence shows peaks corresponding to pure ceria), and ceria with some remnant La doping 270 resulting in XRD peaks at lower angle. Overall, these observations indicate that beyond a 271 threshold concentration of $\sim 10 \%$, it is difficult to stabilize La in the ceria structure in the 272 presence of iron oxide. It is likely that strong interactions between lanthana and iron provide a 273 strong driving force for bleed-out of lanthana which was stable in the ceria structure prior to iron 274 loading. 
275 This is further supported by the average lattice parameters for the support oxides in $\mathrm{Fe}-\mathrm{La}_{\mathrm{x}} \mathrm{Ce}_{1}$ -

$276{ }_{\mathrm{x}} \mathrm{O}_{2-\mathrm{x} / 2}$ calculated from XRD (figure 3b). After iron deposition, the lattice parameter for all

$277 \mathrm{La}_{\mathrm{x}} \mathrm{Ce}_{1-\mathrm{x}} \mathrm{O}_{2-\mathrm{x} / 2}$ oxides decreases. However, the decrease in lattice parameter is small up to $10 \%$

278 La-doping, above which a strong decrease in the lattice parameter is observed, consistent with a

279 significant bleed-out of $\mathrm{La}$ in parallel with the formation of $\mathrm{LaFeO}_{3}$, as confirmed in XRD.

280 (Note that the large standard deviation in the lattice parameters at high La-containing oxides is

281 due to the poorly defined peaks, again suggesting a rather disorganized bleed-out process due to

282 the "scattered" presence of Fe on the support surface, and a much restricted sample space for 283 statistical averaging. 


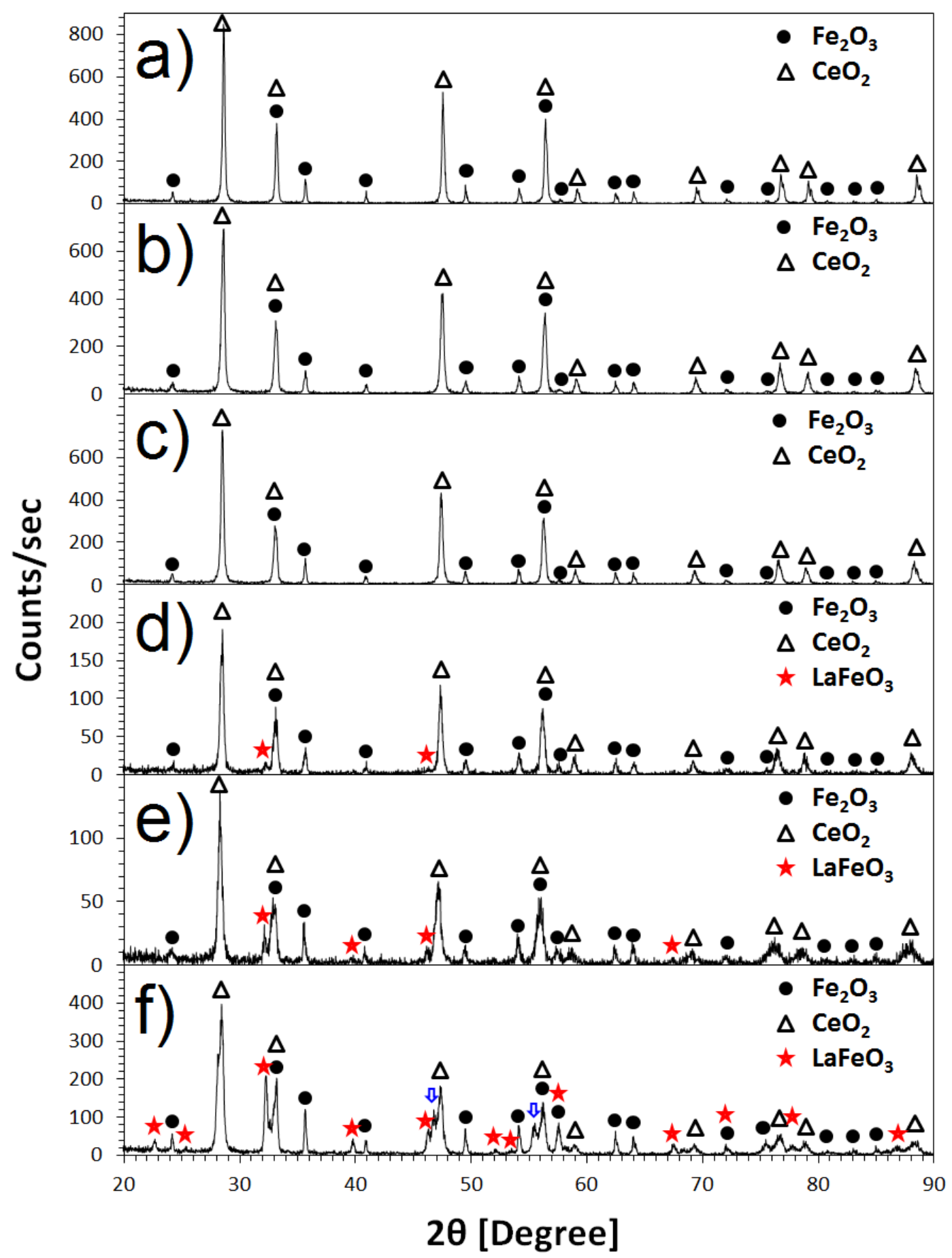

Figure 4: Typical X-ray diffraction pattern of $\mathrm{Fe}-\mathrm{La}_{\mathrm{x}} \mathrm{Ce}_{1-\mathrm{x}} \mathrm{O}_{2-\mathrm{x} / 2}$ carriers, with $\left.\mathrm{x}=\mathrm{a}\right) 0$, b) 0.02 , c) 0.05 , d) 0.1 , e) 0.2 and f) 0.3 , calcined at $900^{\circ} \mathrm{C}$ in air for $2 \mathrm{~h}$. XRD patterns show that a minimum threshold concentration of lanthana is required to observe lanthana bleedout and significant formation of lanthana iron oxide $\left(\mathrm{LaFeO}_{3}\right)$. 


\subsection{Reactive tests in TGA using $\mathrm{H}_{2}$ :}

\section{$287 \quad 3.2 .1$ Redox cycles at $900^{\circ} \mathrm{C}$ :}

288 After establishing the thermal stability of the oxygen carriers at non-reactive conditions, all carrier materials were subjected to redox cycling in a thermogravimetric analyzer (TGA) at $900^{\circ} \mathrm{C}$. CLC operation was simulated by periodically switching between fuel (carrier reduction) and air (oxidation), separated by a purge phase to avoid direct contact of fuel and oxidizing gas. The aim of these studies was to understand thermal stability and redox kinetics of the carriers as

293 a function of La doping into the support. Therefore, $\mathrm{H}_{2}$ was again first used as model fuel to 294 avoid complications arising due to multiple parallel and sequential reaction pathways in the 295 oxidation of methane, including carbon deposition due to fuel pyrolysis.

296 Figure 5a shows 10 redox cycles for $\mathrm{Fe}-\mathrm{La}_{0.1} \mathrm{Ce}_{0.9} \mathrm{O}_{1.95}$ during cyclic operation with $\mathrm{H}_{2}$ and air at $297900^{\circ} \mathrm{C}$. One can see that the carrier shows stable operation over the duration of the experiment as 298 indicated by the unchanged sample weight in the reduced and oxidized state of the carrier over 299 multiple cycles. Similar experiments were performed to confirm the thermal stability of all carriers investigated in this study (not shown). Although some of the carriers had shown bleed-

301 out of lanthana in the calcined state, all carriers were found to show stable operation up to 10 302 cycles, suggesting that - following the initial La bleed - the carrier attains a stable state. Figure 3035 b shows a single cycle in detail for a $\mathrm{Fe}-\mathrm{La}_{0.1} \mathrm{Ce}_{0.9} \mathrm{O}_{1.95}$ carrier. The carrier shows rapid loss of 304 oxygen (i.e. reduction) upon exposure to hydrogen. Interestingly, the sample weight obtained in the reduced state of the carrier is much lower than the expected weight due to full reduction of 306 the iron phase in the carrier (depicted by the bottom-most dotted line in figure 5b), indicating a 307 fractional reduction of the doped ceria of up to $2 \%$ of the total sample weight. 


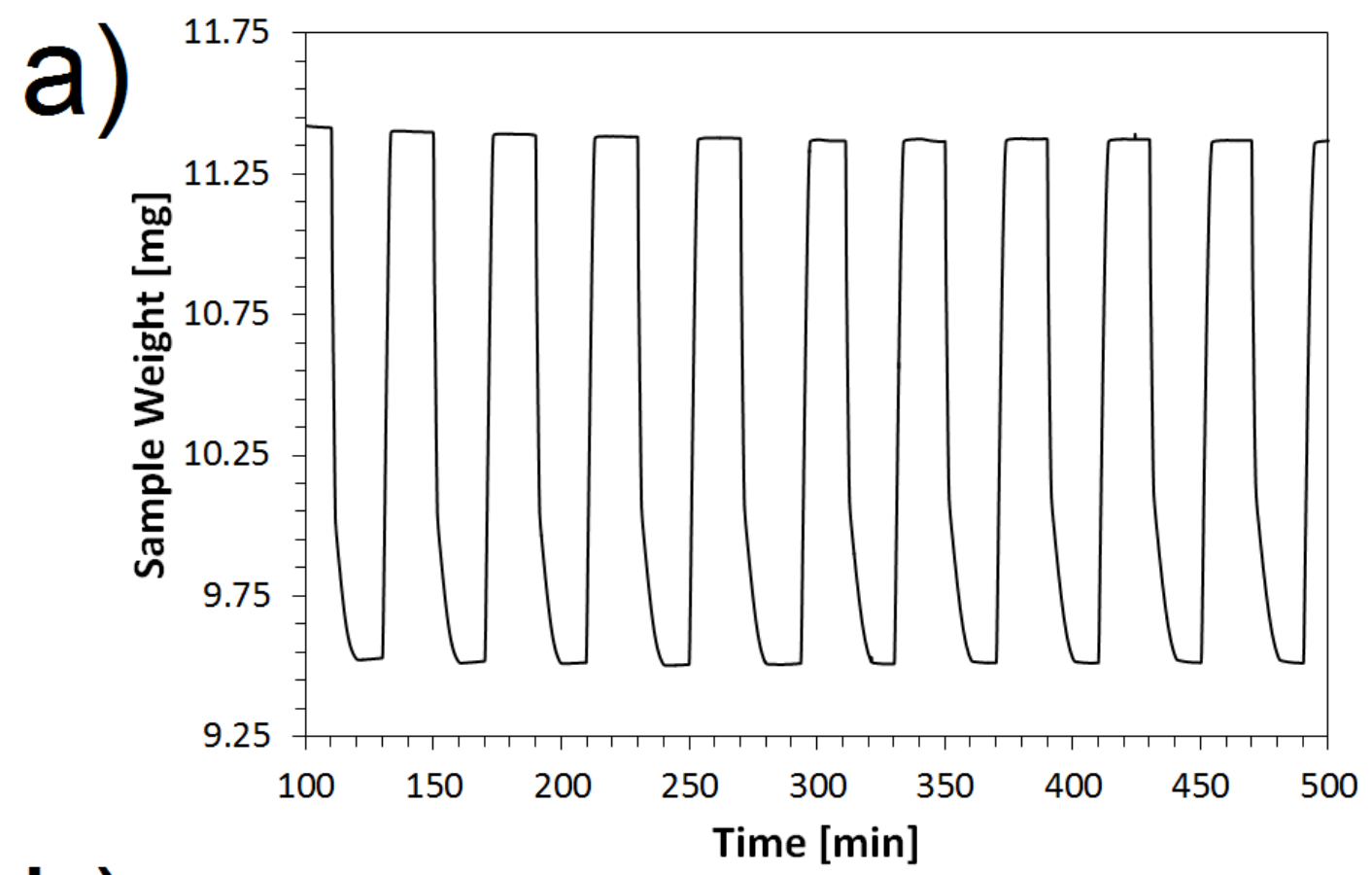

b)

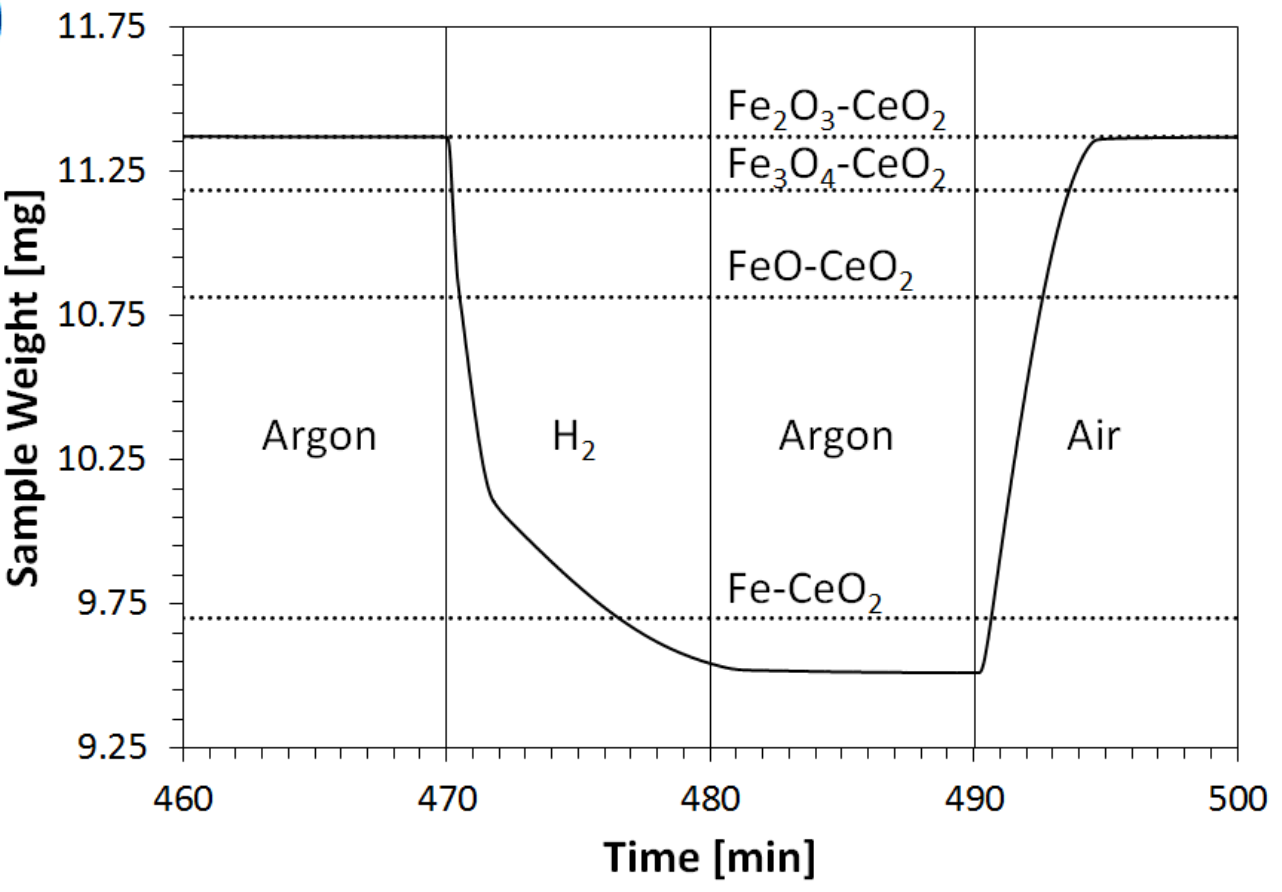

Figure 5: a) Multiple redox cycle and b) a single redox cycle during CLC operation of $\mathrm{Fe}-\mathrm{La}_{0.1} \mathrm{Ce}_{0.9} \mathrm{O}_{1.95}$ in TGA at $900^{\circ} \mathrm{C}$ with reduction in $\mathrm{H}_{2}$, argon purge, and air oxidation $(20 \mathrm{sccm})$. Dotted lines in the panel b show the sample weight that corresponds to various oxidation states of the carrier during redox operation. 


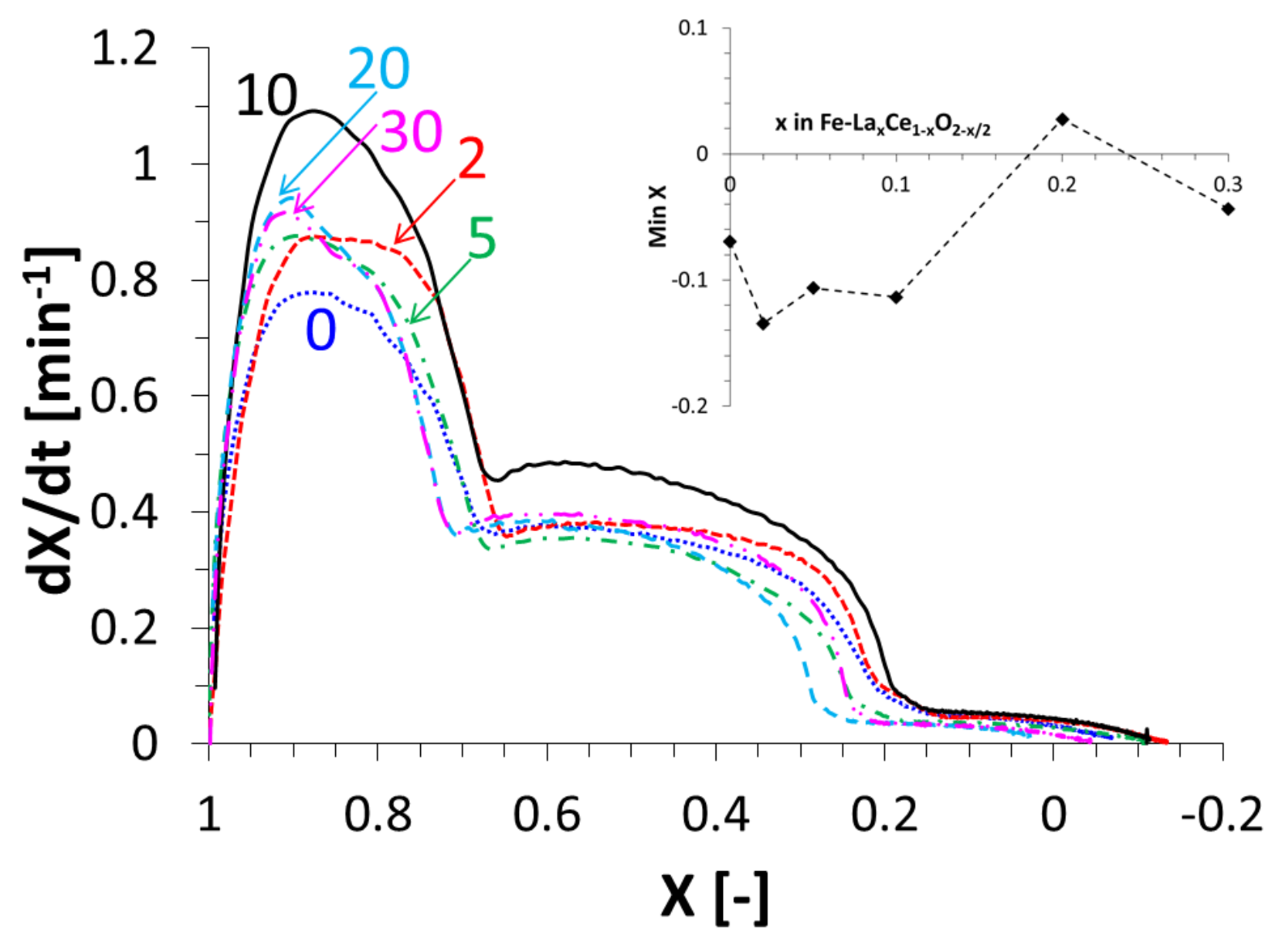

Figure 6: Rate of carrier conversion with respect to time for $\mathrm{Fe}-\mathrm{La}_{\mathrm{x}} \mathrm{Ce}_{1-\mathrm{x}} \mathrm{O}_{2-\mathrm{x} / 2}$ carriers as a function of carrier conversion (X) during reduction half cycle in TGA at $900^{\circ} \mathrm{C}$ using $\mathrm{H}_{2}$ as fuel. Numbers next to the arrows indicate the \%La doping in the lanthana-ceria mixed oxide supports. For better visibility, the inset shows the minimum conversion (i.e. highest degree of reduction) of the carrier as a function of La doping. Low La doping $(0<\% \mathrm{La}<10)$ results in deeper carrier reduction than a further increased doping, as indicated by the "more negative" $\mathrm{X}$. 
310 Previously, we had observed that the use of (undoped) reducible supports yields very limited 311 contribution to the oxygen carrying capacity; however, the oxygen mobility in the support 312 structure resulted in fast redox kinetics and facilitated complete utilization of the supported 313 metal $^{29,30}$. Therefore, the impact of La-doping on the redox kinetics of the overall carrier was 314 evaluated by calculating the rate of reduction of the oxygen carriers. Figure 6 shows the 315 reduction rate $(\mathrm{dX} / \mathrm{dt})$ as a function of the degree of carrier reduction $(\mathrm{X})$ for all carriers, where $\mathrm{X}$ 316 is defined as: $\mathrm{X}=\left(\mathrm{W}(\mathrm{t})-\mathrm{W}_{\text {red }}\right) /\left(\mathrm{W}_{\mathrm{ox}}-\mathrm{W}_{\text {red }}\right)$, with $\mathrm{W}(\mathrm{t})$ denoting the momentary weight of the 317 carrier, $\mathrm{W}_{\mathrm{ox}}$ the carrier weight in the fully oxidized state, and $\mathrm{W}_{\text {red }}$ the carrier weight in the fully 318 reduced state. Importantly, all values are calculated based on the complete reduction of the metal 319 only, thus keeping a consistent reference for the differently doped carriers (which allow 320 reduction of the support to different degrees). Thus, $X=1$ represents the carrier in its fully 321 oxidized state, while $X=0$ indicates that the active metal in the oxygen carrier is fully reduced 322 (without any contribution of the reducibility from support). Measurable contributions of the 323 reducibility of the support beyond the full reduction of the metal phase hence result in $\mathrm{X}<0$ due 324 to the additional decrease in the carrier weight.

325 Overall, all carriers show similar trends for the rate of carrier conversion: A strong maximum in 326 the rate of reduction is observed during the initial stage of carrier reduction $(1<\mathrm{X}<\sim 0.7)$. The 327 boundaries of this rapid reduction regime correspond well with the reduction of $\mathrm{Fe}_{2} \mathrm{O}_{3}(\mathrm{X}=1)$ to $328 \mathrm{FeO}(\mathrm{X}=0.67)$, indicating that the initial reduction of the fully oxidized iron oxide phase 329 proceeds very rapidly and without a detectable transition in the rate corresponding to the 330 formation of a magnetite phase. Subsequent reduction of carrier below FeO is slow and hence 331 characterized by a broad and low rate profile. Finally, the rate of carrier conversion drops almost 332 to zero as the oxygen reservoir is depleted. Although the metal is completely reduced, however, a 
measurable, non-zero rate of oxygen consumption is observed which indicates continued loss of oxygen from the reducible support. Close inspection of the $\mathrm{dX} / \mathrm{dt}$ profile in the final stages of carrier reduction (see inset in figure 6) reveals that small amount of lanthana doping $(0<\%$ La $<$ 10) results in deeper carrier reduction, i.e. enhanced oxygen availability compared to undoped ceria. Although the oxygen contribution from the support is overall small $(\sim 14 \%$ of the total oxygen utilization for $\mathrm{Fe}-\mathrm{La}_{0.1} \mathrm{Ce}_{0.9} \mathrm{O}_{1.95}$ ), low $\mathrm{La}$ doping results in almost doubling of the reducibility of the ceria support. Further increase in the lanthana doping is actually counterproductive and reduces the contribution of support. Furthermore, the rate $d X / d t$ during the initial rapid reduction phase $\left(\mathrm{Fe}_{2} \mathrm{O}_{3} \rightarrow \mathrm{FeO}\right)$ shows similar dependence on lanthana doping concentration, with an initial increase in rate, a maximum at $10 \mathrm{wt} \%$, followed by a decrease at higher doping concentrations.

Following the CLC tests, all carriers were characterized via XRD to test if exposure to the harsh environment of redox cycling affected their phase stability (figure 3c). One can see that up to $10 \%$ La doping there is no significant change in the lattice parameters of the supports after calcination at $900^{\circ} \mathrm{C}$ (figure $3 \mathrm{~b}$ ) and after subsequent exposure to redox cycling using $\mathrm{H}_{2} /$ air at $900^{\circ} \mathrm{C}$ (figure 3c). Furthermore, XRD of these carriers confirms presence of only $\mathrm{Fe}_{2} \mathrm{O}_{3}$ and $\mathrm{CeO}_{2}$ as significant phases (not shown here). Both observations thus confirm good stability of the doped ceria structures at low dopant concentrations. As expected, further increasing the concentration of lanthana doping exacerbates the lanthana bleed-out seen in the unreactive stability tests before, and presence of $\mathrm{LaFeO}_{3}$ is confirmed in XRD.

\subsubsection{Redox cycles at $600^{\circ} \mathrm{C}$ :}


355 From the above comparison of the carriers during redox cycling at $900^{\circ} \mathrm{C}$ it is evident that carrier capacity, reactivity, and stability (i.e. likelihood of $\mathrm{LaFeO}_{3}$ formation) show a strong dependence

357 on the extent of La doping. However, to further elucidate the difference in intrinsic carrier 358 reactivity, additional tests were conducted at low temperature $\left(600^{\circ} \mathrm{C}\right)$ in order to slow down the 359 redox kinetics and hence enhance any intrinsic reactivity differences between the carriers due to 360 oxygen mobility. Figure $7 \mathrm{a}$ and $\mathrm{b}$ shows the carrier conversion profiles during reduction (figure 361 7a) and re-oxidation (figure $7 b$ ), where the numbers next to the curves indicate the respective $362 \%$ La doping. As observed before, low concentrations of La-doping $(0-10 \%)$ strongly accelerate 363 the carrier reduction but result in only marginal improvements in the amount of oxygen available 364 for fuel oxidation. Further increase in the La-doping does not further improve the kinetics but 365 adversely affects the amount of oxygen available for the reduction.

366 The loss in oxygen carrying capacity upon increasing La doping beyond $10 \%$ can be traced back 367 to two effects: On one hand, the reduced amount of ceria available for reduction (lanthana is 368 essentially irreducible at these conditions), and on the other hand the formation of $\mathrm{LaFeO}_{3}$ 369 (which is similarly difficult to reduce). We have previously shown that lanthana is significantly 370 less reducible than ceria ${ }^{47}$, and additional TGA redox cycles using $\mathrm{Fe}-\mathrm{La}_{2} \mathrm{O}_{3}$ (where $\mathrm{LaFeO}_{3}$ is a 371 major phase) at various temperature $\left(400-1000^{\circ} \mathrm{C}\right.$; not shown here $)$ showed that $\mathrm{LaFeO}_{3}$ can be 372 reduced to $\mathrm{Fe}$ and $\mathrm{La}_{2} \mathrm{O}_{3}$ only at sufficiently high temperatures $\left(>700-1000^{\circ} \mathrm{C}\right)$, while it is 373 stable and shows poor reactivity during reduction at low temperature. Therefore, the 374 superposition of the beneficial formation of oxygen vacancies upon doping with these 375 detrimental effects on reducibility result in the observed optimum in the amount of La doping. 

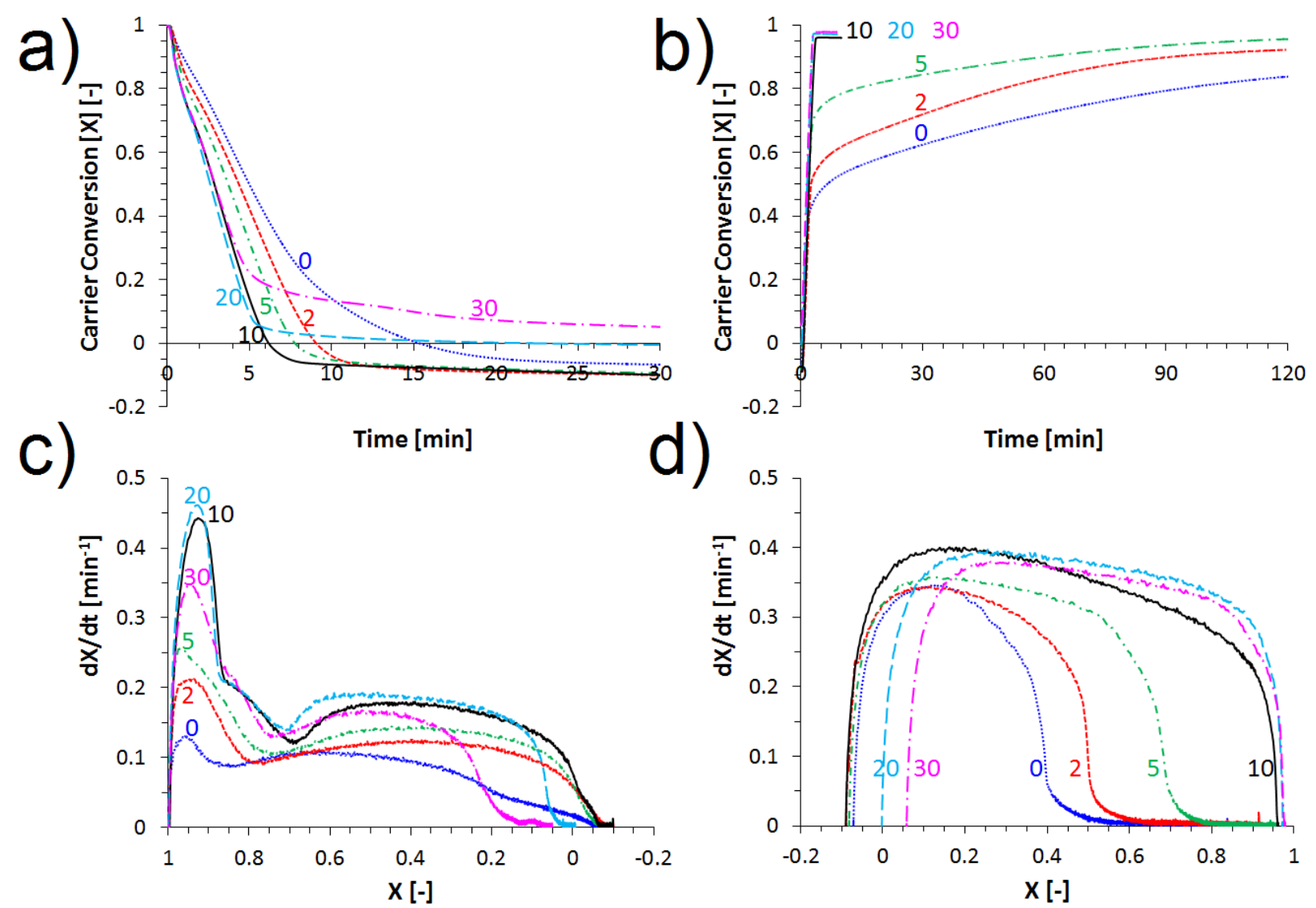

Figure 7: Integral carrier conversion (a, b) and rate of carrier conversion (c, d) during reduction $(\mathrm{a}, \mathrm{c})$ and re-oxidation $(\mathrm{b}, \mathrm{d})$ of $\mathrm{Fe}-\mathrm{La}_{\mathrm{x}} \mathrm{Ce}_{1-\mathrm{x}} \mathrm{O}_{2-\mathrm{x} / 2}$ carriers during redox cycling in TGA at $600^{\circ} \mathrm{C}$ using $\mathrm{H}_{2}$ and air $(20 \mathrm{sccm})$. Numbers next to the curves indicate the \%La-doping in ceria. 
379 Unlike reduction, the oxidation kinetics do not show a maximum at an optimal La concentration:

380 Figure $7 \mathrm{~b}$ and $\mathrm{d}$ show that the integral carrier conversion and conversion rate during air re-

381 oxidation show increasing trends up to $10 \%$ La, beyond which very little detectable change

382 occurs. All carriers with at least 10\%La-doping show very rapid and complete re-oxidation,

383 while carriers with lower dopant levels show extremely slow re-oxidation which hence remains

384 incomplete even over $\sim 2 \mathrm{hrs}$ of re-oxidation. Despite the absence of a kinetic maximum, 10\% La

385 doping again emerges as the optimum as it is the lowest doping level which is sufficient to

386 dramatically accelerate the oxidation rate and achieve complete re-oxidation. Similar fast re-

387 oxidation of carriers was seen with $\mathrm{Ni}-\mathrm{La}_{2} \mathrm{O}_{3}$ at $350^{\circ} \mathrm{C}^{29}$, and $\mathrm{Fe}-\mathrm{La}_{2} \mathrm{O}_{3}$ at $600^{\circ} \mathrm{C}$ (not shown

388 here), confirming that La is the key component for re-oxidation of the carrier.

389 Overall, TGA tests with hydrogen demonstrate that the extent of La doping has significant 390 impact on the stability of the supported metal, its effective oxygen carrying capacity, and on 391 redox kinetics.

\subsection{Reactive tests with $\mathrm{CH}_{4}$ as fuel:}

394 Ultimately, oxygen carriers will be used in the combustion of carbonaceous fuels. We hence 395 extended the studies onto investigation of the redox performance of these carriers with methane 396 as fuel. Based on the trends observed in the hydrogen-fueled redox cycles (discussed above), 0 , 3972 , 10, and 30\% La-doped carriers were down-selected to further corroborate the observation that 398 an optimal concentration of La exists for optimal carrier performance.

\subsubsection{Reactivity tests in TGA:}


400 The down-selected carriers were evaluated in multi-cycle CLC tests at $900^{\circ} \mathrm{C}$ with $\mathrm{CH}_{4}$ as fuel 401 for $6-8$ cycles. All carriers showed stable operation over the duration of the experiment $(\sim 7-8$

402 h). Figure 8 shows a direct comparison of carrier conversion vs time during the reduction half 403 cycle with $\mathrm{CH}_{4}$ for the selected carriers with four different \%La-doping (0, 2, 10, and 30\%). 404 Undoped $\mathrm{Fe}-\mathrm{CeO}_{2}$ takes the longest time for complete reduction of the carrier, while $2 \%$ and $40510 \%$ La doping results in a significant acceleration of the reduction i.e. shorter time for complete 406 reduction of the carrier. Furthermore, close observation of the carrier reduction values at the end 407 of the reduction half cycle reveal that 2 and 10\% La-doped carriers supply more oxygen for the 408 combustion of methane than undoped or $30 \%$ La doped carrier. Thus, irrespective of the fuel 409 used, i.e. $\mathrm{H}_{2}$ or $\mathrm{CH}_{4}$, an excess concentration of La reduces the oxygen carrying capacity and 410 yields less reactive carriers, i.e. in both cases an optimal doping level exists. X-ray diffraction 411 after CLC cycling (not shown) again confirms the tendency of carriers with high La doping to 412 form $\mathrm{LaFeO}_{3}$. In agreement with the $\mathrm{H}_{2}$ experiments, restricting the La-dopant below $10 \%$ is 413 beneficial not only for carrier reactivity and oxygen carrying capacity but also for carrier 414 stability. 


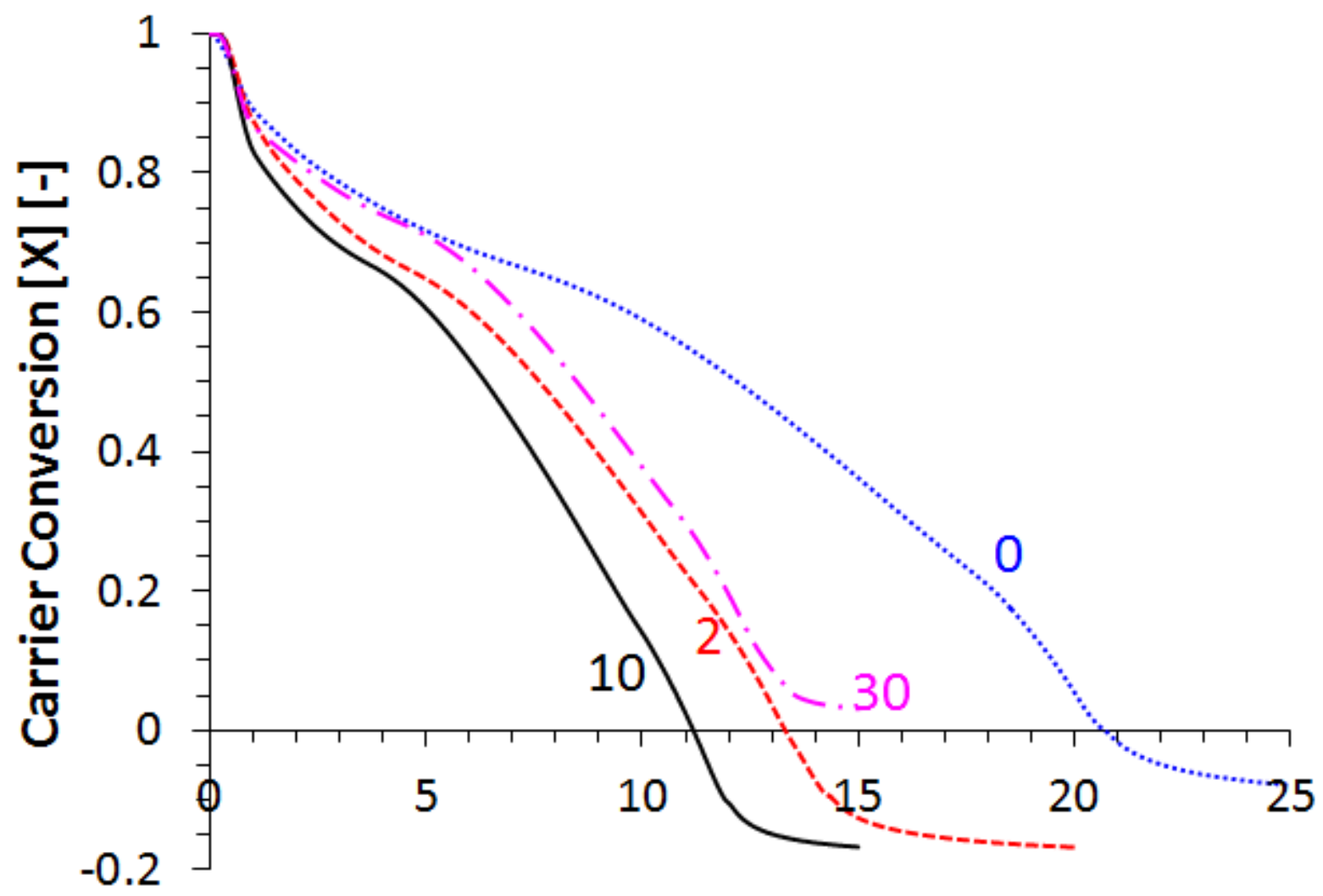

\section{Time [min]}

Figure 8 : Comparison of carrier conversion profiles as a function of $\% \mathrm{La}$-doping for $\mathrm{Fe}-\mathrm{La}_{\mathrm{x}} \mathrm{Ce}_{1}$ ${ }_{x} \mathrm{O}_{2-\mathrm{x} / 2}$ carriers during CLC operation in TGA at $900^{\circ} \mathrm{C}$ with reduction in $\mathrm{CH}_{4}(5 \mathrm{sccm}), \mathrm{N}_{2}$ purge and air oxidation $(20 \mathrm{sccm})$. Numbers next to the curves indicate the \%La-doping in ceria 
417 3.3.2 Reactivity tests in fixed-bed reactor:

418 Although redox cycles in TGA provide useful information about carrier reactivity and stability,

419 TGA experiments are run with large excess of gas phase reactants and do not adequately 420 represent gas-solid contacting patterns in a fixed bed or fluidized bed configuration. Hence, 421 redox cycles in TGA cannot give meaningful insight into fuel conversion and product selectivity 422 in the gas phase. Selective total oxidation of the fuel is important as CLC aims at (near423 )complete carbon capture via total oxidation of fuel to $\mathrm{CO}_{2}$ and steam, while products from 424 undesired side-reactions such as partial oxidation and fuel cracking result in reduced carbon 425 capture efficiency and can result in carrier deactivation. Therefore, $\mathrm{Fe}-\mathrm{La}_{\mathrm{x}} \mathrm{Ce}_{1-\mathrm{x}} \mathrm{O}_{2-\mathrm{x} / 2}$ carriers 426 were next subjected to extended reduction in methane to understand the effect of La doping on 427 fuel conversion and $\mathrm{CO}_{2}$ selectivity.

428 During fixed-bed reactor tests, the oxygen carrier bed was brought to the reaction temperature $429\left(900^{\circ} \mathrm{C}\right)$ and then methane was flown over the pre-oxidized carriers until the carrier was 430 completely reduced, i.e., until the selectivity for total or partial oxidation products $\left(\mathrm{CO}_{2}\right.$ or $\left.\mathrm{CO}\right)$ 431 disappeared and hydrogen (from methane cracking over the reduced metal) was the dominant 432 product. Product gases were analyzed by mass spectrometry. The reactor was then purged with $433 \mathrm{Ar}$ and the carrier was regenerated in synthetic air $\left(20 \% \mathrm{O}_{2}\right.$ in $\left.\mathrm{He}\right)$. During re-oxidation, the 434 evolution of $\mathrm{CO}$ and $\mathrm{CO}_{2}$ indicated carbon burn-off while breakthrough of oxygen indicated 435 complete regeneration of the carrier.

436 Figure 9 compares various $\mathrm{Fe}-\mathrm{La}_{\mathrm{x}} \mathrm{Ce}_{1-\mathrm{x}} \mathrm{O}_{2-\mathrm{x} / 2}$ carriers with regard to total oxidation (i.e. $\mathrm{CO}_{2}$ ) 437 selectivity (figure 9a), rate of methane conversion (figure 9b) and $\mathrm{CO}_{2}$ yield (figure 9c) as 
438 function of relative carrier weight during reduction in the fixed bed reactor. Carrier weight is $439100 \%$ at the start of the reduction half cycle, indicating that oxygen carrier was completely 440 oxidized prior to reduction. Subsequent exposure to methane leads to loss of oxygen resulting in 441 overall drop in the weight of the carriers. The vertical dotted lines in the graphs indicate the 442 relative carrier weight corresponding to various oxidation states of iron in $\mathrm{Fe}-\mathrm{La}_{\mathrm{x}} \mathrm{Ce}_{1-\mathrm{x}} \mathrm{O}_{2-\mathrm{x} / 2}$ with 44340 wt.\% Fe loading.

444 Methane oxidation transitions through various phases of activity and selectivity, which — for the 445 undoped ceria support — can be directly correlated with the oxidation state of Fe. Figure 9a 446 shows that reduction of $\mathrm{Fe}_{2} \mathrm{O}_{3}$ to $\mathrm{Fe}_{3} \mathrm{O}_{4}$ is most selective for total oxidation of methane, while 447 further reduction of the carrier results in a drop in $\mathrm{CO}_{2}$ selectivity with the sharp breaks in $\mathrm{CO}_{2}$ 448 selectivity closely matching the transition from $\mathrm{Fe}_{3} \mathrm{O}_{4}$ to $\mathrm{FeO}$ and $\mathrm{FeO}$ to $\mathrm{Fe}$, respectively. As 449 expected, reduction of undoped $(0 \% \mathrm{La}) \mathrm{Fe}-\mathrm{CeO}_{2}$ stops in close vicinity of the calculated carrier 450 weight for fully reduced metallic iron suggesting little to no contribution from the support 451 material. Comparing this base case with $2 \%$ La-doped carrier, we observe that Fe$452 \quad \mathrm{La}_{0.02} \mathrm{Ce}_{0.95} \mathrm{O}_{1.99}$ shows a qualitatively similar $\mathrm{CO}_{2}$ selectivity profile. However, all the transitions 453 in the $\mathrm{CO}_{2}$ selectivity are strongly shifted towards lower carrier weights, i.e. towards higher 454 oxygen consumption than stoichiometrically required for the transition between the respective 455 iron oxidation states alone. At the end of the reduction half cycle, the oxygen contribution from $456 \mathrm{Fe}-\mathrm{La}_{0.02} \mathrm{Ce}_{0.95} \mathrm{O}_{1.99}$ is almost double that of $\mathrm{Fe}-\mathrm{CeO}_{2}$. Clearly, La-doped ceria strongly 457 contributes oxygen for the combustion of methane. Interestingly, the oxygen contribution from 458 the support structure is quantitatively much higher than that expected for stoichiometric 459 reduction of $\mathrm{CeO}_{2}$ to (thermodynamically stable) $\mathrm{Ce}_{2} \mathrm{O}_{3}$, suggesting that La doping enables non460 stoichiometric reduction of ceria at the operating conditions, i.e. it significantly alters the 
461 thermodynamic stability of ceria. It is furthermore remarkable that the shift of the selectivity

462 "breaks" towards lower carrier weight (i.e. higher oxygen consumption) is already present for the

463 very first transition, i.e. the transition from $\mathrm{Fe}_{2} \mathrm{O}_{3}$ to $\mathrm{Fe}_{3} \mathrm{O}_{4}$. This indicates that the carrier support

464 contributes oxygen to the methane combustion from the very onset of the reaction and not only

465 after the oxygen in the Fe-phase has been depleted. This suggests that the oxygen exchange

466 between the Fe-phase and the support proceeds in a very facile way and agrees with earlier

467 observations that La doping results in the formation of oxygen vacancies which greatly facilitate

468 oxygen transport inside the (doped) ceria lattice ${ }^{36,47}$.

469 The increased oxygen mobility in the support not only enhances oxygen availability but also

470 assists in increasing the carrier reactivity during the $\mathrm{Fe}_{2} \mathrm{O}_{3} \rightarrow \mathrm{Fe}_{3} \mathrm{O}_{4}$ transition that is of concern

471 for CLC operation with Fe-based materials (figure 9b). Compared to undoped $\mathrm{Fe}-\mathrm{CeO}_{2}$, higher

472 reactivity and a larger fraction of the carrier weight that can be used for total oxidation of

473 methane combine to a doubling in both the $\mathrm{CO}_{2}$ yield and the usable carrier weight for $2 \%$ La-

474 doped carrier!

475 

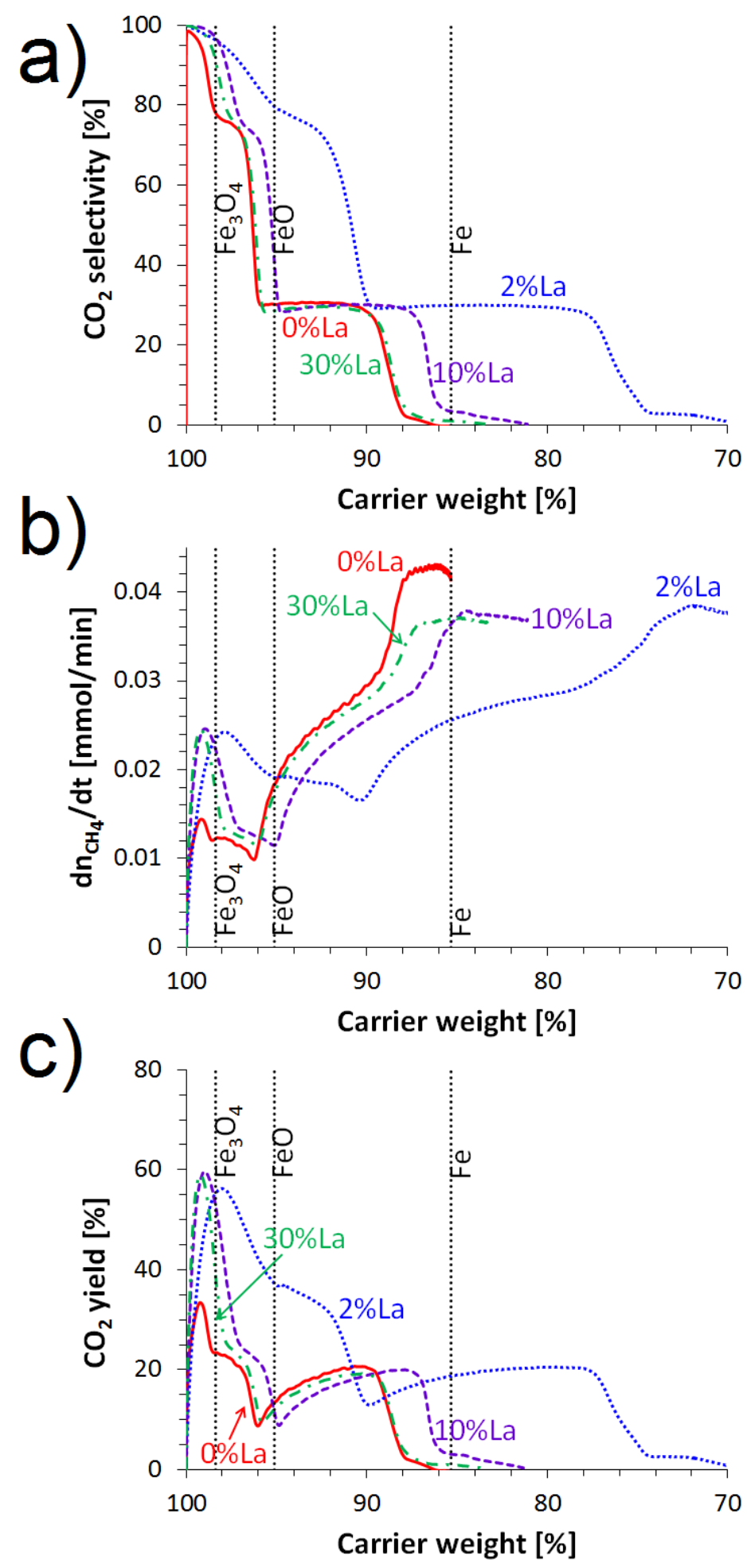

Figure 9: Comparison of a) $\mathrm{CO}_{2}$ selectivity, b) rate of methane conversion and c) $\mathrm{CO}_{2}$ yield as a function of overall carrier weight during reduction of $40 \mathrm{wt} . \% \mathrm{Fe}-\mathrm{La}_{\mathrm{x}} \mathrm{Ce}_{1-\mathrm{x}} \mathrm{O}_{2-\mathrm{x} / 2}$ in fixed bed reactor at $900^{\circ} \mathrm{C}$ using methane (16.7 vol.\%, $\left.1 \mathrm{sccm}\right)$. 
477 In agreement with the TGA studies, a further increase in lanthana doping is not favorable for 478 oxygen carrying capacity and carrier overall performance. Increasing the dopant concentration 479 from 2 to $10 \%$ already results in a significant loss in the overall amount of oxygen that can be 480 extracted from the material, and upon a further increase in the La concentration to $30 \%$ any 481 enhancement disappears and the $\mathrm{CO}_{2}$ selectivity trace closely overlaps with that of $\mathrm{Fe}-\mathrm{CeO}_{2}$. 482 Interestingly, however, the initial activity during the $\mathrm{Fe}_{2} \mathrm{O}_{3} \rightarrow \mathrm{Fe}_{3} \mathrm{O}_{4}$ transition remains strongly 483 increased compared to the undoped carrier (see fig. 9b). In fact, all three doped carrier show 484 similar initial rate enhancements, suggesting that the oxygen mobility enhancement due to La 485 doping remains intact upon increasing the doping. While we have no conclusive evidence for the 486 reasons behind the lower carrier utilization with increasing reactivity, previous work suggests 487 that the low reducibility of lanthana compared to ceria may compensate for the increased oxygen 488 mobility and hence limit overall oxygen availability ${ }^{36,47}$, although our observation of La bleed489 out at higher doping levels (discussed above) offers a possible alternate explanation. Similar 490 enhancement effects have been reported with doping low concentrations of gadolinium ${ }^{31}(10 \%)$ 491 and samarium ${ }^{33}(15 \%)$ into ceria, but the present results underscore that dopant effects cannot be 492 linearly extrapolated and are non-trivial problems with strong dependence on the nature and/or 493 concentration of dopant, operating conditions, etc.

\subsection{Effect of La-doping on redox cyclic stability:}

497 Finally, it can be expected that doping of the support may affect - beyond the reactivity - also 498 the carrier stability during redox cycling. It has been previously reported that doping ceria helps 
abate the deterioration of its textural properties which in turn helps preserve the oxygen defects in the support structure $38,39,45,46$. Therefore, multi-cycle TGA redox tests were used to investigate the effect of La-doping on the redox stability of the carriers at CLC conditions.

Figure 10 compares performance of $\mathrm{Fe}-\mathrm{La}_{0.1} \mathrm{Ce}_{0.9} \mathrm{O}_{1.95}$ and undoped $\mathrm{Fe}-\mathrm{CeO}_{2}$ over 50 cycles using $\mathrm{H}_{2}$ as model fuel at $900^{\circ} \mathrm{C}$. The La-doped carrier shows stable operation, characterized by reproducible carrier weights in successive reduced and oxidized states, and is fully reduced and oxidized during the redox process (as indicated by the dotted lines representing the sample weights in various oxidation state of the metal). Furthermore, as discussed before (section 3.2), the carrier weight in the reduced state dips well below the reference line for metallic iron indicating oxygen contributions from the La-doped reducible support.

In contrast to that, while $\mathrm{Fe}-\mathrm{CeO}_{2}$ appears to be stable over the initial $\sim 11$ cycles, this carrier subsequently shows strong deactivation with incomplete re-oxidation of the carrier. This inability to re-oxidize completely suggests sintering/agglomeration, where the increasing particle size results in increasingly long pathways for solid state diffusion in order to access the oxygen contained in the carrier. This was confirmed upon removal of the sample from the TGA test chamber after the CLC multicycles: The originally finely powdered $\mathrm{Fe}-\mathrm{CeO}_{2}$ carrier was found to be agglomerated into pelletized form after the cyclic redox exposure. Interestingly, however, this agglomeration behavior was similarly observed for the La-doped carrier with both the doped and un-doped carrier showing a BET surface area of $<5 \mathrm{~m}^{2} / \mathrm{g}$ in all cases after multi-cycle exposure. Hence, despite the fact that La-doping does not stabilize a high surface area post redox cycling at $900^{\circ} \mathrm{C}$, the absence of a significant change in the redox kinetics over 50 cycles for the La-doped carrier suggests that La-doping helps to maintain a high oxygen mobility in the support structure and hence keeps the iron oxide phases easily accessible - and hence active for CLC - 
522 even for larger particle sizes. This suggests that such doped support materials might be of 523 particular interest for large-scale CLC application in fluidized bed configuration, where 524 identification of low porosity carriers (which typically show better mechanical stability and 525 attrition stability) with sufficient reactivity is a key concern.

526 

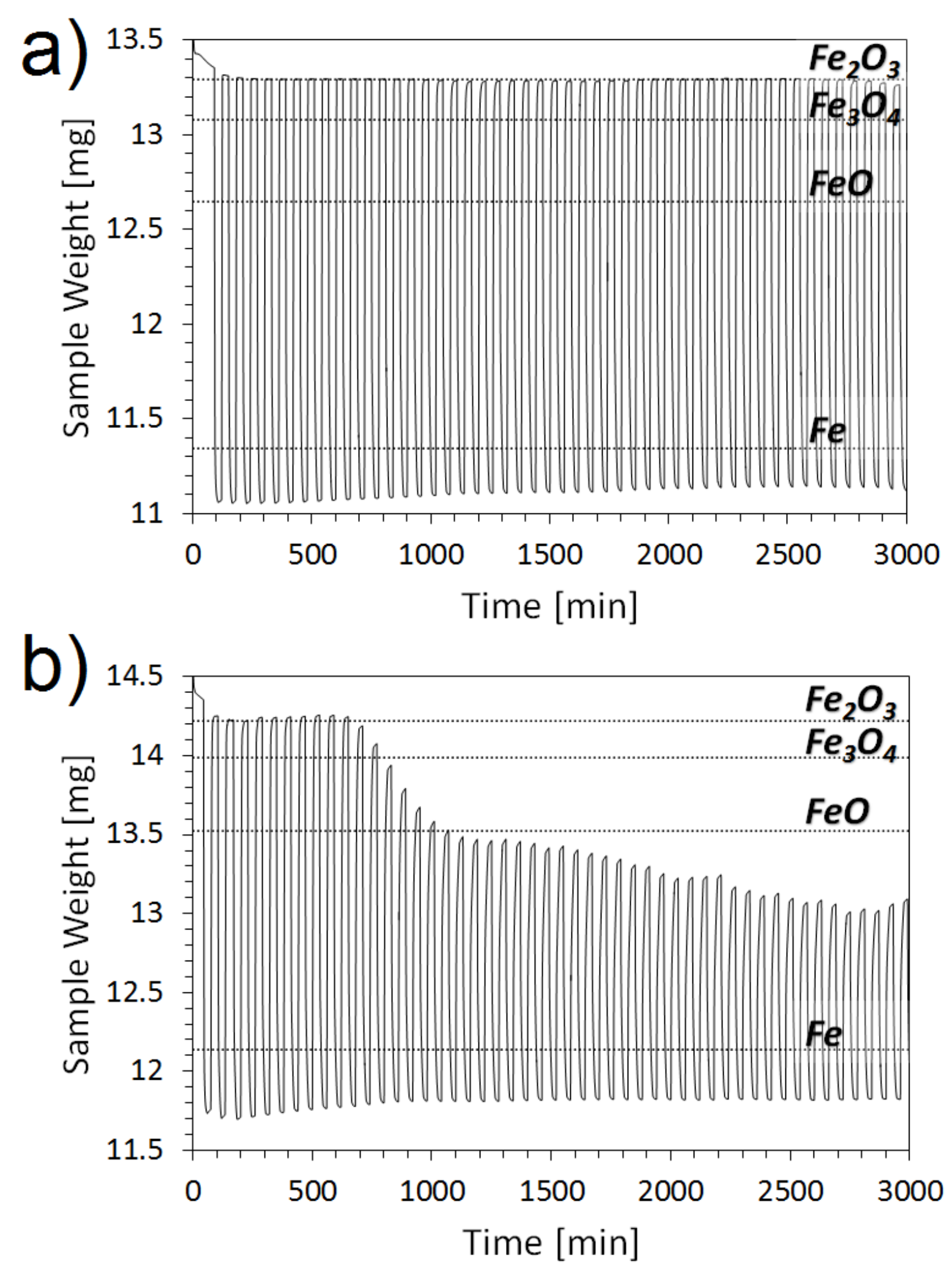

Figure 10: Fifty cycles of CLC redox operation of a) $\mathrm{Fe}-\mathrm{La}_{0.1} \mathrm{Ce}_{0.9} \mathrm{O}_{1.95}$ and b) $\mathrm{Fe}-\mathrm{CeO}_{2}$ at $900^{\circ} \mathrm{C}$ in TGA using $\mathrm{H}_{2}$ as model fuel. $\left(\mathrm{H}_{2}, \mathrm{Ar}\right.$, air $=20 \mathrm{sccm}, 15 \mathrm{~min}$ each $)$. 
$529 \quad 4.0$ Summary

530 The identification of low-cost, highly active and stable oxygen carrier materials is critical for 531 successful implementation of CLC technology in industrial practice. To-date, most studies have 532 focused on monometallic carriers supported on simple oxides. In the present report, the impact of 533 La doping on ceria supports for Fe-based oxygen carriers was investigated, with the aim to 534 identify the effect of doping reducible oxides with an aliovalent dopant to improve oxygen 535 mobility and hence oxygen carrying capacity and reactivity of the carrier in CLC.

536 La-doped ceria supports were synthesized using a straightforward hydrothermal synthesis 537 approach and Fe was deposited onto the support matrix via deposition-precipitation. X-ray 538 diffraction and lattice parameter calculations confirm the formation of a uniform solid solution of 539 lanthana in ceria, i.e. complete incorporation of La into the ceria cubic lattice. Upon deposition 540 of iron onto the La-doped ceria supports, carriers with up to $10 \%$ La showed good thermal 541 stability, while those with $>10 \%$ La doping showed lanthana bleed-out, resulting in the formation 542 of a poorly reducible $\mathrm{LaFeO}_{3}$ phase. During redox cycling, all La-doped carriers showed stable 543 operation over 10 cycles, and extended stability tests (50 cycles) for $\mathrm{Fe}-\mathrm{La}_{0.1} \mathrm{Ce}_{0.9} \mathrm{O}_{1.95}$ and 544 undoped $\mathrm{Fe}-\mathrm{CeO}_{2}$ confirmed that La-doping strongly improves the thermal stability of these 545 carriers.

546 Significantly, the redox kinetics of these carriers shows a strongly non-linear dependence on the 547 dopant concentration. Both oxidation and reduction kinetics are strongly accelerated for low La 548 doping, while for higher doping the oxidation rate remains constant and the carrier reduction rate 549 starts to slow down. The drastic enhancement in carrier oxidation kinetics — which becomes 
550 almost instantaneous upon doping of small amounts of $\mathrm{La}$ - has so far been largely overlooked in

551 the looping community and is a direct indication for the drastic effect of the dopant on oxygen

552 mobility in the ceria lattice. The reduction behavior is similar for $\mathrm{H}_{2}$ and $\mathrm{CH}_{4}$ as fuel, although

553 optimum doping levels for $\mathrm{CH}_{4}$ are slightly lower than for $\mathrm{H}_{2}$ (2\% vs $10 \%$ La, respectively).

554 Interestingly, despite the strong impact on the kinetics, La-doping does not change the $\mathrm{CO}_{2}$

555 selectivity curve qualitatively but the increased availability of oxygen due to doping shifts the

556 selectivity curve towards higher oxygen utilization and hence increases the weight fraction of the

557 carrier usable for CLC. Remarkably, as little as 2\% La doping almost doubles the oxygen

558 carrying capacity of the carriers in CLC of methane. Finally, the oxygen defects/vacancies

559 generated via doping not only accelerate the oxygen transport and increase oxygen utilization,

560 but also create anchor sites for the supported metal and strongly enhance carrier stability over

561 long-term high-temperature cycling.

562 From an application perspective, the present results suggest that doped carrier supports, which

563 have to-date not found much attention in industrial research on chemical looping, offer a range of

564 benefits in return for minimal added carrier cost (due to low dopant concentrations and

565 straightforward synthesis of these carriers). The strong enhancement of both oxidation and

566 reduction kinetics allows reduction of both the reducer reactor and the oxidizer (or further

567 enhancement of reactor throughput), while the increase in accessible oxygen in the carrier allows

568 reduction of the carrier circulation rate. At the same time, enhanced stability will allow

569 utilization of the carrier over more cycles and hence reduction in carrier cost due to carrier

570 replacement.

571 While our studies were limited to La-doped ceria, it seems likely that the results apply to other

572 doped oxides as well, i.e. we expect that doping reducible oxides in order to enhance their 
573 oxygen mobility will result in strong enhancements in carrier reactivity and oxygen carrying 574 capacity, suggesting that doped oxides (and, generally, highly oxygen-conductive oxide 575 supports) offer vast possibilities for improvement of existing oxygen carriers for CLC. Such

576 carriers could hence offer some of the advantages of other emerging oxygen carriers with high 577 oxygen mobility, such as perovskites, while being based on simple, well-established, and

578 inexpensive synthesis procedures ${ }^{62,65}$. However, the strongly non-linear dependence of thermal 579 stability, oxygen carrying capacity, and reactivity on the extent of doping also underscores the 580 importance of thorough analysis of such doped carriers and the need for an improved 581 fundamental understanding of the complex underlying gas-solid and solid-solid reactive 582 processes.

\section{Acknowledgements:}

584 This technical effort was in parts performed in support of the U.S. Department of Energy's 585 National Energy Technology Laboratory's on-going research under the RDS contract DE-AC26586 04NT41817. Furthermore, financial support by the National Science Foundation (CBET $587 \quad \# 1159853)$ and by the University of Pittsburgh's Mascaro Center for Sustainable Innovation is 588 gratefully acknowledged. 
$590 \quad$ 1. World Energy Outlook. In IEA (International Energy Agency): 2015.

591 2. Zeng, L.; Luo, S.; Sridhar, D.; Fan, L.-S., Chemical looping processes-particle characterization, 592 ionic diffusion-reaction mechanism and reactor engineering. Reviews in chemical engineering 2012, 28, 593 (1), 1-42. (http://dx.doi.org/10.1515/revce-2011-0010)

$594 \quad 3 . \quad$ Adanez, J.; Abad, A.; Garcia-Labiano, F.; Gayan, P.; de Diego, L. F., Progress in Chemical-Looping 595 Combustion and Reforming technologies. Progress in Energy and Combustion Science 2012, 38, (2), 215596 282. (http://dx.doi.org/10.1016/i.pecs.2011.09.001)

5974 4. Moghtaderi, B., Review of the Recent Chemical Looping Process Developments for Novel Energy 598 and Fuel Applications. Energy \& Fuels 2012, 26, (1), 15-40. (http://dx.doi.org/10.1021/ef201303d)

600 5. Hossain, M. M.; de Lasa, H. I., Chemical-looping combustion (CLC) for inherent CO2 separationsa review. Chem. Eng. Sci. 2008, 63, (18), 4433-4451. (http://dx.doi.org/10.1016/j.ces.2008.05.028)

6. Anheden, M.; Svedberg, G., Exergy analysis of chemical-looping combustion systems. Energy Conversion and Management 1998, 39, (16-18), 1967-1980. (http://dx.doi.org/10.1016/s01968904(98)00052-1)

$6047 . \quad$ Kvamsdal, H. M.; Jordal, K.; Bolland, O., A quantitative comparison of gas turbine cycles with 605 CO(2) capture. Energy 2007, 32, (1), 10-24. (http://dx.doi.org/10.1016/j.energy.2006.02.006)

8. Naqvi, R.; Wolf, J.; Bolland, O., Part-load analysis of a chemical looping combustion (CLC) combined cycle with CO2 capture. Energy 2007, 32, (4), 360-370. (http://dx.doi.org/10.1016/j.energy.2006.07.011)

609 9. Wolf, J.; Anheden, M.; Yan, J. Y., Comparison of nickel- and iron-based oxygen carriers in chemical looping combustion for $\mathrm{CO} 2$ capture in power generation. Fuel 2005, 84, (7-8), 993-1006. (http://dx.doi.org/10.1016/i.fuel.2004.12.016)

613 10. Adanez, J.; de Diego, L. F.; Garcia-Labiano, F.; Gayan, P.; Abad, A.; Palacios, J. M., Selection of oxygen carriers for chemical-looping combustion. Energy \& Fuels 2004, 18, (2), 371-377. (http://dx.doi.org/10.1021/ef0301452)

614

11. Adánez, J.; Gayán, P.; Celaya, J.; de Diego, L. F.; García-Labiano, F.; Abad, A., Chemical Looping Combustion in a $10 \mathrm{kWth}$ Prototype Using a CuO/Al2O3 Oxygen Carrier: Effect of Operating Conditions on Methane Combustion. Industrial \& Engineering Chemistry Research 2006, 45, (17), 6075-6080. (http://dx.doi.org/10.1021/ie060364l)

620 12. Linderholm, C.; Mattisson, T.; Lyngfelt, A., Long-term integrity testing of spray-dried particles in a 10-kW chemical-looping combustor using natural gas as fuel. Fuel 2009, 88, (11), 2083-2096. (http://dx.doi.org/10.1016/i.fuel.2008.12.018)

13. Lyngfelt, A., Chemical-looping combustion of solid fuels - Status of development. Applied Energy 2014, 113, 1869-1873. (http://dx.doi.org/http://dx.doi.org/10.1016/j.apenergy.2013.05.043)

624 14. Lyngfelt, A., Oxygen Carriers for Chemical Looping Combustion - $4000 \mathrm{~h}$ of Operational 625 Experience. Oil Gas Sci. Technol. - Rev. IFP Energies nouvelles 2011, 66, (2), 161-172. 626 (http://dx.doi.org/10.2516/ogst/2010038)

627 15. Pröll, T.; Bolhàr-Nordenkampf, J.; Kolbitsch, P.; Hofbauer, H., Syngas and a separate 628 nitrogen/argon stream via chemical looping reforming - A $140 \mathrm{~kW}$ pilot plant study. Fuel 2010, 89, (6), 629 1249-1256. (http://dx.doi.org/10.1016/j.fuel.2009.09.033)

630 16. Rifflart, S.; Hoteit, A.; Yazdanpanah, M. M.; Pelletant, W.; Surla, K., Construction and operation 631

632

633

634 of a $10 \mathrm{~kW} \mathrm{CLC}$ unit with circulation configuration enabling independent solid flow control. Energy Procedia 2011, 4, 333-340. (http://dx.doi.org/10.1016/j.egypro.2011.01.059)

17. Tong, A.; Bayham, S.; Kathe, M. V.; Zeng, L.; Luo, S.; Fan, L.-S., Iron-based syngas chemical looping process and coal-direct chemical looping process development at Ohio State University. Applied 635 Energy 2014, 113, 1836-1845. (http://dx.doi.org/10.1016/j.apenergy.2013.05.024) 
18. Cho, P.; Mattisson, T.; Lyngfelt, A., Comparison of iron-, nickel-, copper- and manganese-based oxygen carriers for chemical-looping combustion. Fuel 2004, 83, (9), 1215-1225. (http://dx.doi.org/10.1016/i.fuel.2003.11.013)

19. Garcia-Labiano, F.; Adanez, J.; de Diego, L. F.; Gayan, P.; Abad, A., Effect of pressure on the behavior of copper-, iron-, and nickel-based oxygen carriers for chemical-looping combustion. Energy \& Fuels 2006, 20, (1), 26-33. (http://dx.doi.org/10.1021/ef050238c)

20. Jerndal, E.; Mattisson, T.; Lyngfelt, A., Thermal analysis of chemical-looping combustion. Chem. Eng. Res. Des. 2006, 84, (A9), 795-806. (http://dx.doi.org/10.1205/cherd05020)

21. Mattisson, T.; Lyngfelt, A.; Cho, P., The use of iron oxide as an oxygen carrier in chemical-looping combustion of methane with inherent separation of CO2. Fuel 2001, 80, (13), 1953-1962. (http://dx.doi.org/10.1016/s0016-2361(01)00051-5)

22. Mattisson, T.; Jardnas, A.; Lyngfelt, A., Reactivity of some metal oxides supported on alumina with alternating methane and oxygen-application for chemical-looping combustion. Energy \& Fuels 2003, 17, (3), 643-651. (http://dx.doi.org/10.1021/ef020151i) Synthesis of a solid looping material of NiO/NiAl2O4. Industrial \& Engineering Chemistry Research 1999, 38, (1), 126-132. (http://dx.doi.org/10.1021/ie9803265)

653 24. Mattisson, T.; Johansson, M.; Lyngfelt, A., The use of $\mathrm{NiO}$ as an oxygen carrier in chemicallooping combustion. Fuel 2006, 85, (5-6), 736-747. (http://dx.doi.org/10.1016/i.fuel.2005.07.021)

25. Sedor, K. E.; Hossain, M. M.; de Lasa, H. I., Reactivity and stability of Ni/Al2O3 oxygen carrier for chemical-looping combustion (CLC). Chem. Eng. Sci. 2008, 63, (11), 2994-3007. (http://dx.doi.org/10.1016/j.ces.2008.02.021)

658 26. Zafar, Q.; Mattisson, T.; Gevert, B., Redox investigation of some oxides of transition-state metals $659 \mathrm{Ni}, \mathrm{Cu}, \mathrm{Fe}$, and $\mathrm{Mn}$ supported on SiO2 and MgAl2O4. Energy \& Fuels 2006, 20, (1), 34-44. 660

661

662

663 (http://dx.doi.org/10.1021/ef0501389)

27. Mattisson, T.; Johansson, M.; Lyngfelt, A., Multicycle reduction and oxidation of different types of iron oxide particles - Application to chemical-looping combustion. Energy \& Fuels 2004, 18, (3), 628637. (http://dx.doi.org/10.1021/ef0301405)

28. Bhavsar, S.; Najera, M.; Solunke, R.; Veser, G., Chemical looping: To combustion and beyond. Catalysis Today, (0). (http://dx.doi.org/10.1016/j.cattod.2013.12.025)

29. Bhavsar, S.; Veser, G., Reducible Supports for Ni-based Oxygen Carriers in Chemical Looping Combustion. Energy \& Fuels 2013, 27, (4), 2073-2084. (http://dx.doi.org/10.1021/ef400184b)

30. Bhavsar, S.; Veser, G., Bimetallic Fe-Ni Oxygen Carriers for Chemical Looping Combustion. Industrial \& Engineering Chemistry Research 2013, 52, (44), 15342-15352. (http://dx.doi.org/10.1021/ie400612g)

31. Hedayati, A.; Azad, A.-M.; Rydén, M.; Leion, H.; Mattisson, T., Evaluation of Novel CeriaSupported Metal Oxides As Oxygen Carriers for Chemical-Looping Combustion. Industrial \& Engineering Chemistry Research 2012, 51, (39), 12796-12806. (http://dx.doi.org/10.1021/ie300168j)

32. Chueh, W. C.; Falter, C.; Abbott, M.; Scipio, D.; Furler, P.; Haile, S. M.; Steinfeld, A., High-Flux Solar-Driven Thermochemical Dissociation of $\mathrm{CO} 2$ and H2O Using Nonstoichiometric Ceria. Science 2010, 330, (6012), 1797-1801. (http://dx.doi.org/10.1126/science.1197834)

33. Chueh, W. C.; Haile, S. M., Ceria as a Thermochemical Reaction Medium for Selectively Generating Syngas or Methane from H2O and CO2. Chemsuschem 2009, 2, (8), 735-739. (http://dx.doi.org/10.1002/cssc.200900138)

681 Science and Engineering 1996, 38, (4), 439-520. (http://dx.doi.org/10.1080/01614949608006464) 
35. Kaspar, J.; Fornasiero, P.; Hickey, N., Automotive catalytic converters: current status and some perspectives. Catalysis Today 2003, 77, (4), 419-449. (http://dx.doi.org/10.1016/s0920-5861(02)00384$\underline{x})$

36. Liang, S.; Veser, G., Mixed Lanthana/Ceria Nanorod-Supported Gold Catalysts for Water-GasShift. Catalysis Letters 2012, 142, (8), 936-945. (http://dx.doi.org/10.1007/s10562-012-0845-x)

37. Fu, Q.; Saltsburg, H.; Flytzani-Stephanopoulos, M., Active nonmetallic Au and Pt species on ceriabased water-gas shift catalysts. Science 2003, 301, (5635), 935-938. (http://dx.doi.org/10.1126/science.1085721)

38. Pengpanich, S.; Meeyoo, V.; Rirksomboon, T.; Bunyakiat, K., Catalytic oxidation of methane over $\mathrm{CeO} 2-\mathrm{ZrO} 2$ mixed oxide solid solution catalysts prepared via urea hydrolysis. Applied Catalysis A: General 2002, 234, (1-2), 221-233. (http://dx.doi.org/10.1016/S0926-860X(02)00230-2)

39. Zhu, T. L.; Flytzani-Stephanopoulos, M., Catalytic partial oxidation of methane to synthesis gas over Ni-CeO2. Appl. Catal. A-Gen. 2001, 208, (1-2), 403-417. (http://dx.doi.org/10.1016/s0926$860 \times(00) 00728-6)$

40. Dong, W.-S.; Jun, K.-W.; Roh, H.-S.; Liu, Z.-W.; Park, S.-E., Comparative Study on Partial Oxidation of Methane over Ni/ZrO2, Ni/CeO2 and Ni/Ce-ZrO2 Catalysts. Catalysis Letters 2002, 78, (1-4), 215-222. (http://dx.doi.org/10.1023/A:1014905318290)

41. Vayssilov, G. N.; Lykhach, Y.; Migani, A.; Staudt, T.; Petrova, G. P.; Tsud, N.; Skala, T.; Bruix, A.; Illas, F.; Prince, K. C.; Matolin, V.; Neyman, K. M.; Libuda, J., Support nanostructure boosts oxygen transfer to catalytically active platinum nanoparticles. Nature Materials 2011, 10, (4), 310-315. (http://dx.doi.org/10.1038/nmat2976)

42. Wang, X. Q.; Shen, M. Q.; Wang, J.; Fabris, S., Enhanced Oxygen Buffering by Substitutional and Interstitial Ni Point Defects in Ceria: A First-Principles DFT plus U Study. Journal of Physical Chemistry C 2010, 114, (22), 10221-10228. (http://dx.doi.org/10.1021/jp101100f)

43. Inaba, H.; Tagawa, H., Ceria-based solid electrolytes. Solid State Ionics 1996, 83, (1-2), 1-16. (http://dx.doi.org/10.1016/0167-2738(95)00229-4)

44. Mogensen, M.; Sammes, N. M.; Tompsett, G. A., Physical, chemical and electrochemical properties of pure and doped ceria. Solid State lonics 2000, 129, (1-4), 63-94. (http://dx.doi.org/10.1016/S0167-2738(99)00318-5)

45. Fornasiero, P.; Balducci, G.; Di Monte, R.; Kašpar, J.; Sergo, V.; Gubitosa, G.; Ferrero, A.; Graziani, M., Modification of the Redox Behaviour of CeO2Induced by Structural Doping with ZrO2. Journal of Catalysis 1996, 164, (1), 173-183. (http://dx.doi.org/10.1006/jcat.1996.0373)

46. Mamontov, E.; Egami, T.; Brezny, R.; Koranne, M.; Tyagi, S., Lattice defects and oxygen storage capacity of nanocrystalline ceria and ceria-zirconia. Journal of Physical Chemistry B 2000, 104, (47), 11110-11116. (http://dx.doi.org/10.1021/jp0023011)

47. Liang, S.; Broitman, E.; Wang, Y.; Cao, A.; Veser, G., Highly stable, mesoporous mixed lanthanum-cerium oxides with tailored structure and reducibility. Journal of Materials Science 2011, 46, (9), 2928-2937. (http://dx.doi.org/10.1007/s10853-010-5168-y)

48. Hernández, W. Y.; Laguna, O. H.; Centeno, M. A.; Odriozola, J. A., Structural and catalytic properties of lanthanide (La, Eu, Gd) doped ceria. Journal of Solid State Chemistry 2011, 184, (11), 30143020. (http://dx.doi.org/10.1016/j.jssc.2011.09.018)

49. Yahiro, H.; Eguchi, K.; Arai, H., Electrical properties and reducibilities of ceria-rare earth oxide systems and their application to solid oxide fuel cell. Solid State Ionics 1989, 36, (1-2), 71-75. (http://dx.doi.org/10.1016/0167-2738(89)90061-1)

50. Eguchi, K.; Setoguchi, T.; Inoue, T.; Arai, H., Electrical properties of ceria-based oxides and their application to solid oxide fuel cells. Solid State lonics 1992, 52, (1), 165-172. (http://dx.doi.org/10.1016/0167-2738(92)90102-U) 
51. Yahiro, H.; ohuchi, T.; Eguchi, K.; Arai, H., Electrical properties and microstructure in the system ceria-alkaline earth oxide. Journal of Materials Science 1988, 23, (3), 1036-1041. (http://dx.doi.org/10.1007/BF01154008)

52. Yahiro, H.; Eguchi, Y.; Eguchi, K.; Arai, H., Oxygen ion conductivity of the ceria-samarium oxide system with fluorite structure. Journal of Applied Electrochemistry 1988, 18, (4), 527-531. (http://dx.doi.org/10.1007/BF01022246)

53. Wang, D. Y.; Park, D. S.; Griffith, J.; Nowick, A. S., Oxygen-ion conductivity and defect interactions in yttria-doped ceria. Solid State lonics 1981, 2, (2), 95-105. (http://dx.doi.org/10.1016/0167-2738(81)90005-9)

738 54. Le Gal, A.; Abanades, S.; Bion, N.; Le Mercier, T.; Harlé, V., Reactivity of Doped Ceria-Based Mixed Oxides for Solar Thermochemical Hydrogen Generation via Two-Step Water-Splitting Cycles. Energy \& Fuels 2013, 27, (10), 6068-6078. (http://dx.doi.org/10.1021/ef4014373)

55. Scheffe, J. R.; Jacot, R.; Patzke, G. R.; Steinfeld, A., Synthesis, Characterization, and Thermochemical Redox Performance of $\mathrm{Hf} 4+, \mathrm{Zr} 4+$, and Sc3+ Doped Ceria for Splitting CO2. The Journal of Physical Chemistry C 2013, 117, (46), 24104-24114. (http://dx.doi.org/10.1021/ip4050572)

56. Gibbons, W. T.; Venstrom, L. J.; De Smith, R. M.; Davidson, J. H.; Jackson, G. S., Ceria-based electrospun fibers for renewable fuel production via two-step thermal redox cycles for carbon dioxide splitting. Physical Chemistry Chemical Physics 2014, 16, (27), 14271-14280. (http://dx.doi.org/10.1039/C4CP01974A)

$748 \quad 57 . \quad$ Li, K.; Wang, H.; Wei, Y.; Yan, D., Syngas production from methane and air via a redox process using Ce-Fe mixed oxides as oxygen carriers. Applied Catalysis B: Environmental 2010, 97, (3-4), 361372. (http://dx.doi.org/10.1016/j.apcatb.2010.04.018)

58. Li, K.; Wang, H.; Wei, Y.; Yan, D., Transformation of methane into synthesis gas using the redox property of Ce-Fe mixed oxides: Effect of calcination temperature. International Journal of Hydrogen

59. Myung, J.-h.; Shin, T. H.; Huang, X.; Carins, G.; Irvine, J. T. S., Enhancement of redox stability and electrical conductivity by doping various metals on ceria, $\mathrm{Ce} 1-\mathrm{xMxO2}-\delta(\mathrm{M}=\mathrm{Ni}, \mathrm{Cu}, \mathrm{Co}, \mathrm{Mn}, \mathrm{Ti}, \mathrm{Zr}$ ). International Journal of Hydrogen Energy 2015, 40, (35), 12003-12008. (http://dx.doi.org/10.1016/j.ijhydene.2015.05.029)

60. Rydén, M.; Lyngfelt, A.; Mattisson, T.; Chen, D.; Holmen, A.; Bjørgum, E., Novel oxygen-carrier materials for chemical-looping combustion and chemical-looping reforming; LaxSr1-xFeyCo1-yO3- $\delta$ perovskites and mixed-metal oxides of $\mathrm{NiO}, \mathrm{Fe} 2 \mathrm{O} 3$ and $\mathrm{Mn304}$. International Journal of Greenhouse Gas Control 2008, 2, (1), 21-36. (http://dx.doi.org/10.1016/S1750-5836(07)00107-7)

61. Nalbandian, L.; Evdou, A.; Zaspalis, V., La1-xSrxMyFe1-yO3- $\delta$ perovskites as oxygen-carrier materials for chemical-looping reforming. International Journal of Hydrogen Energy 2011, 36, (11), 66576670. (http://dx.doi.org/10.1016/j.ijhydene.2011.02.146)

62. Galinsky, N. L.; Shafiefarhood, A.; Chen, Y.; Neal, L.; Li, F., Effect of support on redox stability of iron oxide for chemical looping conversion of methane. Applied Catalysis B: Environmental 2015, 164, 371-379. (http://dx.doi.org/10.1016/i.apcatb.2014.09.023)

63. Fleming, P.; Farrell, R. A.; Holmes, J. D.; Morris, M. A., The Rapid Formation of La(OH)3 from La2O3 Powders on Exposureto Water Vapor. Journal of the American Ceramic Society 2010, 93, (4), 1187-1194. (http://dx.doi.org/10.1111/i.1551-2916.2009.03564.x)

64. Shannon, R., Revised effective ionic radii and systematic studies of interatomic distances in halides and chalcogenides. Acta Crystallographica Section A 1976, 32, (5), 751-767. (http://dx.doi.org/10.1107/S0567739476001551)

65. Sarshar, Z.; Kleitz, F.; Kaliaguine, S., Novel oxygen carriers for chemical looping combustion: La $1-\mathrm{x}$ Ce $\mathrm{x}$ BO $3(\mathrm{~B}=\mathrm{Co}, \mathrm{Mn})$ perovskites synthesized by reactive grinding and nanocasting. Energy \& Environmental Science 2011, 4, (10), 4258-4269. (http://dx.doi.org/10.1039/C1EE01716K ) 